\title{
Loss of VGLUT3 Produces Circadian-Dependent Hyperdopaminergia and Ameliorates Motor Dysfunction and L-Dopa-Mediated Dyskinesias in a Model of Parkinson's Disease
}

\author{
Christopher B. Divito, ${ }^{1}$ Kathy Steece-Collier, ${ }^{3}$ Daniel T. Case, ${ }^{1}$ Sean-Paul G. Williams, ${ }^{1}$ Jennifer A. Stancati, ${ }^{3}$ \\ Lianteng Zhi, ${ }^{4}$ Maria E. Rubio, ${ }^{2}$ Caryl E. Sortwell, ${ }^{3}$ Timothy J. Collier, ${ }^{3}$ David Sulzer, ${ }^{5}$ Robert H. Edwards, ${ }^{6}$ Hui Zhang, ${ }^{4}$ \\ and Rebecca P. Seal ${ }^{1,2}$ \\ ${ }^{1}$ Department of Neurobiology and ${ }^{2}$ Department of Otolaryngology, University of Pittsburgh School of Medicine, Pittsburgh, Pennsylvania 15260, ${ }^{3}$ Michigan \\ State University, College of Human Medicine, Department of Translational Science and Molecular Medicine and The Udall Center of Excellence in \\ Parkinson's Disease Research, Grand Rapids, Michigan 49503, ${ }^{4}$ Department of Neuroscience, Jefferson College of Medicine, Thomas Jefferson University, \\ Philadelphia, Pennsylvania 19107, ${ }^{5}$ Departments of Neurology, Psychiatry, and Pharmacology, Columbia University, New York, New York 10032, and \\ ${ }^{6}$ Departments of Neurology and Physiology, University of California, San Francisco School of Medicine, San Francisco, California 94143
}

The striatum is essential for many aspects of mammalian behavior, including motivation and movement, and is dysfunctional in motor disorders such as Parkinson's disease. The vesicular glutamate transporter 3 (VGLUT3) is expressed by striatal cholinergic interneurons (CINs) and is thus well positioned to regulate dopamine (DA) signaling and locomotor activity, a canonical measure of basal ganglia output. We now report that VGLUT3 knock-out (KO) mice show circadian-dependent hyperlocomotor activity that is restricted to the waking cycle and is due to an increase in striatal DA synthesis, packaging, and release. Using a conditional VGLUT3 KO mouse, we show that deletion of the transporter from CINs, surprisingly, does not alter evoked DA release in the dorsal striatum or baseline locomotor activity. The mice do, however, display changes in rearing behavior and sensorimotor gating. Elevation of DA release in the global KO raised the possibility that motor deficits in a Parkinson's disease model would be reduced. Remarkably, after a partial 6-hydroxydopamine (6-OHDA)-mediated DA depletion ( 70\% in dorsal striatum), KO mice, in contrast to WT mice, showed normal motor behavior across the entire circadian cycle. L-3,4-dihydroxyphenylalanine-mediated dyskinesias were also significantly attenuated. These findings thus point to new mechanisms to regulate basal ganglia function and potentially treat Parkinson's disease and related disorders.

Key words: acetylcholine; basal ganglia; dopamine; glutamate; Parkinson's; VGLUT3

Significance Statement

Dopaminergic signaling is critical for both motor and cognitive functions in the mammalian nervous system. Impairments, such as those found in Parkinson's disease patients, can lead to severe motor deficits. Vesicular glutamate transporter 3 (VGLUT3) loads glutamate into secretory vesicles for neurotransmission and is expressed by discrete neuron populations throughout the nervous system. Here, we report that the absence of VGLUT3 in mice leads to an upregulation of the midbrain dopamine system. Remarkably, in a Parkinson's disease model, the mice show normal motor behavior. They also show fewer abnormal motor behaviors (dyskinesias) in response to L-3,4-dihydroxyphenylalanine, the principal treatment for Parkinson's disease. The work thus suggests new avenues for the development of novel treatment strategies for Parkinson's disease and potentially other basal-ganglia-related disorders. 


\section{Introduction}

Basal ganglia circuits are important for motor planning, learning, and motivation. Within the basal ganglia, the striatum receives major cortical and thalamic glutamatergic input, as well as a dense innervation from midbrain dopamine (DA) neurons. These inputs converge onto striatal medium spiny neurons (MSNs), the major output neurons. Also shaping striatal output are a number of interneurons, including cholinergic interneurons (CINs), also referred to as tonically active neurons, which are sparse but form a dense arborization and are temporally aligned with the activity of DA neurons.

The striatum is also central to a number of neurodegenerative disorders, including Parkinson's disease, which is characterized by a loss of substantia nigra pars compacta DA neurons that project to the dorsal striatum. This loss produces motor deficits such as rigidity, tremor, altered gait, bradykinesia, and dysphagia. Treatments for the disorder have included anticholinergic drugs (Gomeza et al., 1999) and the DA precursor L-3,4dihydroxyphenylalanine (L-dopa). However, side effects make these therapies difficult to tolerate, including unwanted motor movements known as dyskinesias, which often arise from escalating doses of L-dopa (Zhuang et al., 2013). New approaches to the treatment of Parkinson's disease are thus still of great interest.

Vesicular glutamate transporter isoform 3 (VGLUT3) is one of three proteins that packages glutamate into secretory vesicles for regulated release (Fremeau et al., 2002; Gras et al., 2002; Schäfer et al., 2002; Gras et al., 2008; Seal et al., 2008). VGLUT1 or VGLUT2 is present at most excitatory nerve terminals, whereas VGLUT3 has a more discrete expression pattern. Within the striatum, cholinergic interneurons express the transporter (Fremeau et al., 2004) and, interestingly, VGLUT3-mediated cotransport of glutamate enhances vesicular acetylcholine (ACh) content (Gras et al., 2008). Therefore, deletion of VGLUT3 from these cells not only abolishes the glutamate signaling (Higley et al., 2011), but also markedly reduces cholinergic transmission (Nelson et al., 2014). However, the role of the glutamate signaling remains unclear.

It was reported previously that VGLUT3 KO mice are hyperlocomotive (Gras et al., 2008), a phenotype that is often associated with increased midbrain DA signaling and is thus potentially relevant to other basal-ganglia-related behaviors such as reward, movement, memory, and motivation. Given the classically assumed antagonistic relationship between striatal acetylcholine and DA (DeBoer et al., 1996; Ding et al., 2006; Surmeier and Graybiel, 2012), it was suggested that the low vesicular ACh tone in CINs of the KO could lead to dysregulation of DA signaling and hyperlocomotor activity. However, specific deletion of the

Received June 2, 2015; revised 0ct. 2, 2015; accepted Oct. 9, 2015.

Author contributions: C.B.D., K.S.-C., D.S., R.H.E., H.Z., and R.P.S. designed research; C.B.D., K.S.-C., D.T.C. S.-P.G.W., J.A.S., L.Z., C.E.S., and H.Z. performed research; C.B.D., K.S.-C., D.T.C., S.P.G.W., M.E.R., T.J.C., H.Z., and R.P.S. analyzed data; C.B.D. and R.P.S. wrote the paper.

The work was funded by the National Institutes of Health (Postdoctoral Training Grant T32DA031111 to C.B.D. and National Institute of Neurological Disorders and Stroke Grant R01 NS082650 to R.P.S.), Michigan State University Translational Science and Molecular Medicine Start Up Funds (T.J.C., K.S.C., and C.E.S.), the Edwin Brophy Endowment at Michigan State University (T.J.C.), and University of Pittsburgh, Department of Neurobiology Startup Funds (R.P.S.). We thank Charlene Yuan, Natalie Cagle, and Tracy Sun for technical assistance; Shenin Dettwyler and Chad Eckard for mouse colony maintenance; Simon Watkins for help with spine imaging; Ray Johnson and Ginger Milne at the Vanderbilt Neurochemistry Core; Nigel Killeen at the UCSF Transgenic Core; and the Gladstone Institute Transgenic Core.

The authors declare no competing financial interests.

Correspondence should be addressed to Rebecca P. Seal, Department of Neurobiology, University of Pittsburgh School of Medicine, 3501 Fifth Avenue, 6058 BST3, Pittsburgh, PA 15260. E-mail: rpseal@pitt.edu.

DOI:10.1523/JNEUROSCI.2124-15.2015

Copyright $\odot 2015$ the authors $\quad 0270-6474 / 15 / 3514984-17 \$ 15.00 / 0$ vesicular acetylcholine transporter (VAChT) in cholinergic interneurons had no effect on baseline locomotor activity (Guzman et al., 2011), raising the possibility that loss of CIN-mediated glutamate signaling causes DA dysregulation and hyperlocomotor activity.

Using a combination of electrophysiology, histology, biochemistry, and behavior, we now show that VGLUT3 KO mice are markedly hyperlocomotive only during the waking cycle. Consistent with this, striatal DA synthesis and release are also significantly elevated only during this time. In addition, using a conditional VGLUT3 KO mouse, we rule out the possibility that the loss of glutamate signaling by cholinergic interneurons serves as the basis for the upregulation of the midbrain DA system. Deletion of VGLUT3 in cholinergic neurons does, however, interfere with sensorimotor gating and habituation of rearing. Because increased striatal DA and decreased ACh signaling have therapeutic implications for Parkinson's disease, we investigated whether the KO mice would show reduced motor symptoms in a model of the disease and, indeed, the mice lacked the motor deficits normally caused by DA depletion and also showed a marked attenuation of L-dopa-mediated dyskinesias.

\section{Materials and Methods}

Animals. Animals were housed in micro-isolator cages on a standard $12 \mathrm{~h}$ sleep/wake cycle (7:00 A.M. lights on, 7:00 P.M. lights off). For day/night behavioral experiments, animals were housed for at least 1 month before testing in a separate room with a different sleep/wake cycle (1:00 A.M. lights on, 1:00 P.M. lights off). All animals were provided ad libitum access to food and water and were treated in compliance with Institutional Animal Care and Use Committees for University of Pittsburgh and University of California-San Francisco, with the Declaration of Helsinki, and with the Institute for Laboratory Animal Research of the National Academy of Science's Guide for the Care and Use of Laboratory Animals and were approved by the Institutional Animal Care and Use Committee at Michigan State University, where L-dopa-induced dyskinesia (LID) studies were performed, and by the Institutional Animal Care and Use Committee at Thomas Jefferson University, where the fast-scan cyclic voltammetry (FSCV) was conducted. All efforts were made to minimize the number of animals used and to avoid pain or discomfort. Mice 6-24 weeks of age were used for experiments. In each experiment, approximately equal numbers of males and females of each genotype were tested unless otherwise stated. ChAT-Cre(G) (stock \#GM60Gsat) mice were obtained from GENSAT. ChAT-IRES-Cre (stock \#018957) Rosa26-FLP (stock \#003946) and Rosa26-Cre (stock \#006054) mice were all obtained from Jackson Laboratories. Slc17a8 ${ }^{-1-}$ mice (also referred to as Vglut $3^{-1-}$ or VGLUT3 KO mice) mice were backcrossed at least eight generations to C57BL/6. Mice with the conditional Vglut3 allele (i.e., $V g l u t 3^{\mathrm{fl} / \mathrm{fl}}$ and $V g l u t 3^{\Delta / \Delta}$ ) were originally derived from 129/Ola ES cells and C57BL/6J blastocysts (described in detail below). Founders were backcrossed three generations to C57BL/6J. Experiments were performed and comparisons made only between littermates (i.e., identical background strains): Slc17a $8^{-1-}$ mice to their Slc17a $8^{+/+}$(also referred to as glut $^{+/+}$or WT) littermates and Slc17a $8^{f l / f l}$;choline O-acetyltransferase ${ }^{\mathrm{Cre} /+}\left(\right.$ Vglut $^{\mathrm{fl} / \mathrm{fl}} ;$ Chat $\left.^{\mathrm{Cre} /+}\right)$ to their Cre-negative $\left(\right.$ Vglut $\left.3^{\mathrm{fl} / \mathrm{fl}}\right)$ littermates.

To generate the conditional VGLUT3 KO mouse line $\left(\operatorname{Vglut} 3^{\mathrm{fl} / \mathrm{fl}}\right), 5^{\prime}$ and $3^{\prime}$ arms of the targeting construct were designed to allow Credependent deletion of exon 2 of the Slc17a8 gene. This exon encodes the first luminal loop and second transmembrane domain and was deleted in the global VGLUT3 KO. Arms of $2.9 \mathrm{~kb}$ (left) and $4.0 \mathrm{~kb}$ (right) were isolated from a C57BL/6J RPCI-24 bacterial artificial chromosome clone (BacPac) and subcloned into the targeting vector, pB6 (gift from Nirao Shah). LoxP sites were designed around exon 2. Positive and negative selection relied on the thymidine kinase promotor-neomyocin gene cassette located between the two arms and the diphtheria toxin subunit A gene downstream of the right arm, respectively. The final targeting plasmid was electroporated into 129/Ola embryonic stem (ES) cells. ES cells 
were screened by Southern blot analysis for the left and right arms to identify founder ES cell lines. DNA was harvested from each ES cell colony and digested overnight with BamH1 restriction enzyme (New England Biolabs). Digested DNA was loaded onto a $0.8 \%$ agarose gel, bands separated by gel electrophoresis and then transferred to Zeta Probe GT Membrane (Bio-Rad Laboratories) using the alkaline capillary method. The blot was neutralized and then incubated in prehybridization solution for $1 \mathrm{~h}$ at $65^{\circ} \mathrm{C}$. Probes were made using Random Primers DNA labeling kit (Life Technologies) and $\alpha^{32}$ P-labeled dCTP (3000 Ci/ mmol; PerkinElmer). Blots were hybridized overnight at $65^{\circ} \mathrm{C}$, washed $4 \times$ at $65^{\circ} \mathrm{C}$ according to the manufacturer's instructions, and then subjected to autoradiography. ES cell founder lines were injected into pseudopregnant C57BL/6J females to give rise to chimeric founders. Two chimeric founders germline transmitted the modified Slc17a8 gene. These founders were bred to the germline Rosa $26^{\mathrm{Flp}}$ mouse to delete the Tk-Neo gene in the germline.

To genotype for the floxed allele, primers surrounding the loxP site (forward: atgtggatgggaaaccagaa and reverse: atagcagctggcacaccagt) were used to generate an $\sim 300$ bp band. A WT band of $\sim 260$ bp can also be detected with these primers. To detect the delta allele, primers to sequences outside of both loxP sites were used (forward: agtccaaggtcccagttggt and reverse: ctggggtactgcacctcact) to generate an $\sim 300 \mathrm{bp}$ band.

Behavior. Unless otherwise stated, both male and female mice with ages ranging from 6 to 24 weeks were used for all behavioral analyses. Light conditions and temperature were kept at ambient levels ( $\sim 32$ lux, $\left.75^{\circ} \mathrm{F}\right)$.

For home cage locomotor activity, mice were placed in rat microisolator cages inside a photobeam monitoring system (Kinder Scientific) for $48 \mathrm{~h}$ with ad libitum access to food and water.

For open-field analysis, mice were allowed to acclimate to the room environment for $15 \mathrm{~min}$ before being placed in an open chamber $(17 \times$ 17 inch) with $x-y-z$ photobeam monitoring (Motor Monitor). Ambulations and rearing behavior were recorded in $1 \mathrm{~min}$ bins for a total of 60 $\mathrm{min}$. The open field was subdivided into peripheral and center zones and analyzed separately, but typically pooled. Mice were retested for 2 subsequent days at the same time of day. The open-field apparatus was also used to measure locomotor activity for $7 \mathrm{~h}$ across the day/night cycle.

For the cylinder test, mice were acclimated to environment for $30 \mathrm{~min}$ with food and water ad libitum. A mouse was placed in a clear acrylic cylinder $\sim 8 \mathrm{~cm}$ in diameter on top of a clear acrylic sheet. The video camera was underneath and recorded 15 min video per animal. The number of contacts made with each forepaw against the cylinder wall was recorded and the number expressed as a percentage of total contacts. Only full weight-bearing contacts were counted, identified by full contact of cylinder with majority of paw. Animals were tested 3-4 h before and 3-4 $\mathrm{h}$ after the start of the waking cycle on separate days.

For rotational analysis, spontaneous clockwise (CW) or counterclockwise $(\mathrm{CCW})$ rotations, mice were placed in the open field with low light conditions ( $\sim 32$ lux). Mice were allowed to freely explore the chamber and $x-y$ beam breaks (Motor Monitor) were recorded for $15 \mathrm{~min}$. Turning that broke beams in a $>112^{\circ}$ arc in either direction was scored as a rotation.

Prepulse inhibition of acoustic startle was measured by placing mice into a soundproof chamber (Kinder Scientific Startle Monitor). After 5 min of white noise acclimation, mice were exposed to randomized trials of $500 \mathrm{~ms}$ exposures to $75,85,95,105$, or 115 decibel sound pressure level (dB SPL) with a $500 \mathrm{~ms}$ intertrial interval. For prepulse inhibition of acoustic startle, mice were exposed to randomized trials of $80 \mathrm{~ms}$ of 65 , $67,69,70,71,73,75,80$, or $85 \mathrm{~dB}$ SPL, $280 \mathrm{~ms}$ before being exposed to $115 \mathrm{~dB}$ SPL noises. Trials were repeated between seven and eight times for each mouse in a randomized order. Startle was measured as the maximum force in Newtons $(\mathrm{N})$ and the average response across the trial repetitions for each mouse were used for data analysis.

Stereotaxic surgery and 6-OHDA-mediated DA depletion. Unilateral dorsal striatal lesions were made to assess parkinsonian motor behavior. Mice (12-24 weeks of age) were anesthetized by inhalation of 3\% isoflurane (Butler Schein) and surgery was performed using aseptic techniques. Stereotaxic coordinates used for the unilateral injection of $6 \mu \mathrm{g}$ 6-OHDA HBr (Sigma-Aldrich) were (in mm) +0.85 AP, $-1.75 \mathrm{ML}$, and
$-2.75 \mathrm{DV}$. Three-minute incubation periods were used between injection needle placement, $2 \mu \mathrm{l}$ injection of $6 \mu \mathrm{g}$ of 6-OHDA, and removal of the injection needle. Immediately after surgery, mice were sutured and administered carprofen subcutaneously (Ketofen, $5 \mathrm{mg} / \mathrm{kg}$ ) and allowed to recover overnight in a heated cage with ad libitum access to water, milled pellets mixed with water (mush), bacon softies (LBS Biotechnology), and banana baby food (Gerber). Mice also received a subcutaneous injection of sterile $0.9 \%$ saline $(0.5 \mathrm{ml}) 1-2 \times$ daily for $7-10 \mathrm{~d}$ after surgery. Mouse weight was monitored and any that lost $>20 \%$ of their presurgical weight were excluded. No animals were lost or euthanized after surgery due to complications. Animals with less than a $50 \%$ decrease in tyrosine hydroxylase $(\mathrm{TH})$ levels across the rostral-caudal extent of the dorsal striatum were excluded from analysis (4 mice total). Behavioral assays were performed 1-3 weeks after 6-OHDA injections. After the behavioral testing, mice were euthanized and brains were harvested for TH analysis. In a subset of animals, 1.6-mm-diameter tissue punches were quickly taken from the dorsal and ventral striatum (2-mmthick coronal section) both ipsilateral and contralateral sides, immediately frozen on dry ice, and sent for HPLC analysis of norepinephrine, epinephrine, 3,4-dihydroxyphenylacetic acid (DOPAC), 5-hydroxyindoleacetic acid (5-HIAA), homovanillic acid (HVA), serotonin (5-HT), and 3-methoxytyramine (3-MT). HPLC measurements were performed by the Vanderbilt Neurochemistry Core Facility. Residual striatal sections (30 $\mu \mathrm{m}$ thick) were used for subsequent immunohistochemical analysis of TH levels.

For quantitation of DA tissue content, animals were euthanized at $\sim$ 10:00 P.M. (night) or $\sim 12: 00$ P.M. (day), the striatum dissected on ice, and then immediately frozen on dry ice and sent for HPLC analysis for biogenic amines as described above.

For immunohistochemistry, mice were anesthetized with a lethal dose of a ketamine/xylazine mixture and transcardially perfused with $25 \mathrm{ml}$ of PBS, followed by $30 \mathrm{ml}$ of a solution of cold PBS containing the following (in $\mathrm{mM}$ ): $137 \mathrm{NaCl}, 2.7 \mathrm{KCl}, 10.1 \mathrm{Na}_{2} \mathrm{HPO}_{4}$, and $1.8 \mathrm{KH}_{2} \mathrm{PO}_{4}$ plus $4 \%$ paraformaldehyde (PFA). Whole brains were dissected and incubated in PBS $+4 \%$ PFA overnight at $4^{\circ} \mathrm{C}$. Brains were then cryoprotected by $3 \mathrm{~d}$ incubation in $30 \%$ sucrose solution at $4^{\circ} \mathrm{C}$. Brains were mounted and sectioned into $30 \mu \mathrm{m}$ slices using a cryostat (Microm HM550) and placed directly into wells. For fluorescent labeling, slices were incubated in PBS containing 5\% normal donkey serum (NDS) and 1\% Triton X-100 for $1 \mathrm{~h}$ at room temperature (RT). Slices were then transferred to PBS $+5 \%$ NDS $+1 \%$ Triton X-100 containing various primary antibodies (described below) overnight at $4^{\circ} \mathrm{C}$. After washing, Alexa Fluor-conjugated secondary antibodies (Jackson ImmunoResearch) were incubated for $1 \mathrm{~h}$ at RT. After washing, slices were mounted with Fluoromount-G (Southern Biotech) and coverslipped. Primary antibodies used consisted of guinea pig $\alpha$-VGLUT3 1:2500 (Edwards Laboratory), goat $\alpha$-ChAT 1:1000 (Millipore), rabbit $\alpha$-TH 1:1000 (Millipore), mouse $\alpha$-glutamic acid decarboxylase (65 kDa) 1:1000 (Millipore), and/or mouse $\alpha$-glutamic acid decarboxylase (67 kDa) 1:1000 (Millipore).

For L-dopa-induced dyskinesias in rodents, severe $(>80 \%)$ DA depletion is necessary to allow the maladaptive changes linked to LID to occur (Cenci et al., 2002; Bastide et al., 2015). Therefore, mice were rendered parkinsonian via unilateral stereotaxic injection of the DA neurotoxin 6 -OHDA into the medial forebrain bundle $(\mathrm{mfb})$. The $\mathrm{mfb}$ coordinates were $-1.3 \mathrm{AP}, 1.1 \mathrm{ML}$, and -5.4 DV. Animals were anesthetized before surgery with an intraperitoneal injection of ketamine/xylazine (100 $\mathrm{mg} / \mathrm{kg}$ ketamine, $20 \mathrm{mg} / \mathrm{kg}$ xylazine in $0.9 \%$ sterile saline; $0.1 \mathrm{cc} / 10 \mathrm{~g}$ ) and placed in a mouse stereotaxic frame. The 6-OHDA ( $5 \mathrm{mg}$ of 6-OHDA $\mathrm{HBr} / \mathrm{ml} 0.9 \%$ sterile saline containing $0.2 \mathrm{mg} / \mathrm{ml}$ ascorbic acid) was injected at a rate of $0.5 \mathrm{nl} / \mathrm{min}(1.5 \mu \mathrm{l}$ total $)$ using a $5 \mathrm{ml}$ Hamilton syringe with a 26 gauge needle. Immediately after surgery, mice were administered carprofen subcutaneously (Rimadyl, $5 \mathrm{mg} / \mathrm{kg}, 0.1 \mathrm{cc} / 10 \mathrm{~g}$ ) and 0.5 $\mathrm{ml}$ of sterile lactated Ringer's solution. For 1 week before surgery, mice were acclimated to a liquefied "food slurry" (water-soaked Purina rat chow pellets, Bioserve bacon-flavored rodent soft dough diet supplement, and Gerber baby food bananas, 1:1:1). Starting the day of surgery, mice were given food slurry, which was prepared fresh daily in a blender and provided $2 \times$ daily (Monday through Friday) until body weights were stable and weight gain steady. Mice also received subcutaneous 
injection of sterile $0.9 \%$ saline $(0.5 \mathrm{ml}) 1-2 \times$ daily for $7-10 \mathrm{~d}$ after surgery. Survival rates were $87.5 \%$ and, of these mice, $84.3 \%$ were successfully lesioned $(\mathrm{DA}$-depletion $=93.3 \pm 1.2 \%$, mean $\pm \mathrm{SEM})$.

LIDs refer to abnormal involuntary movements including dystonia, hyperkinesia, and/or stereotypies noted in parkinsonian mice in response to L-dopa administered after DA depletion by 6-OHDA lesioning. The details of these behaviors and the rating scale used were reported previously (Steece-Collier et al., 2003; Maries et al., 2006). To assess the effects of knocking out VGLUT3 on LID development and expression, mice received a daily (Monday through Friday) injection of L-dopa (1, 2, and $3 \mathrm{mg} / \mathrm{kg}$ ) plus the peripheral decarboxylase inhibitor benserazide (12 $\mathrm{mg} / \mathrm{kg}$ ) in sterile saline over the time course depicted in Figure 9. A given dose of L-dopa was administered for 1 week with dyskinetic behaviors rated over the time course of LID expression (e.g., 20 to $100 \mathrm{~min}$ after injection) and on Monday, Wednesday, and Friday. The same individual who was blinded to treatment conditions and genotype performed the LID ratings. Animals were assessed in a randomized order that was assigned at the beginning of the experiment and maintained for the duration. As detailed previously (Steece-Collier et al., 2003; Maries et al., 2006), both the intensity $(0=$ absent, $1=$ mild, $2=$ moderate, $3=$ severe) and frequency ( $0=$ absent, $1=<50 \%$ of rating period, $2=50 \%$ of the rating period, $3=$ constant) were determined for the following individual components of LID behavior: forelimb hyperkinesia, forelimb dystonia, hindlimb dystonia, trunk dystonia, neck dystonia, and orolingual dyskinesia. A final LID severity score for any given individual component of the LID behavior was obtained by multiplying frequency $\times$ intensity. A total daily severity score for each animal was computed by adding the severity scores of the individual LID behaviors. A total weekly LID score for each animal was computed by averaging the daily severity score for Monday, Wednesday, and Friday ratings.

To assess levels of TH, every sixth coronal section was stained with antisera against the enzyme to visualize DA cells (Soderstrom et al., 2010). Midbrain sections were incubated with TH primary antibody (1: 4000; Millipore) for $24 \mathrm{~h}$ at RT, followed by $90 \mathrm{~min}$ in goat anti-mouse biotinylated IgG (1:400; Millipore) and developed using 0.05\% 3,3'diaminobenzadine. To quantify the degree of nigral $\mathrm{TH}^{+}$neuron depletion, stereological probes were applied using a BX52 Olympus microscope equipped with Microbrightfield stereological software and a Microfire CCD camera (Optronics) using the optical fractionator method according to previously published methods (Madhavan et al., 2012). Cells were counted under the $60 \times$ oil-immersion objective. $\mathrm{TH}^{+}$ cells were counted in sections $480 \mu \mathrm{m}$ apart using a grid size of $195 \times 85 \mu \mathrm{m}$ and counting frame size of $50 \times 50 \mu \mathrm{m}$. The Gundersen method for calculating the coefficient of error was used to estimate the accuracy of the optical fractionator results. The coefficients were generally $<0.1$. The total number of $\mathrm{TH}^{+}$cells in the substantia nigra was compared between genotypes.

To measure levels of TH after unilateral DA depletion in the dorsal striatum, $30-\mu \mathrm{m}$-thick coronal sections across the rostral caudal extent of the striatum were immunostained with rabbit anti-TH (1:1000; Millipore). TH Immunoreactivity was quantified from a threshold-subtracted binary image using imageJ software. TH measurement on the ipsilateral side was normalized to the control contralateral side.

Biochemistry. To prepare striatal synaptosomes, striatal tissue was harvested on ice from $\operatorname{Vglut}^{\mathrm{fl} / \mathrm{fl}} ;$ Chat $^{\mathrm{Cre}(\mathrm{G}) /+}$ and $\operatorname{Vglut}^{\mathrm{fl} / \mathrm{fl}}$ (4-6 mice each) and manually homogenized 10 strokes in homogenization buffer $(320 \mathrm{~mm}$ sucrose, 4 mm HEPES, pH 7.3) + complete protease inhibitors tablet (Roche). Lysate was spun at $900 \times g$ for $10 \mathrm{~min}$ at $4^{\circ} \mathrm{C}$, the supernatant $(\mathrm{S} 1)$ transferred to a new Microfuge tube, and then spun at 10,000 $\times g$ for $15 \mathrm{~min}$ at $4^{\circ} \mathrm{C}$. The resulting pellet (P2) was resuspended in homogenization buffer and a BCA protein concentration assay performed to normalize total protein content. Samples ( $45 \mu \mathrm{g}$ of protein) were diluted in Laemmli sample buffer containing $5 \% \beta$-mercaptoethanol and loaded onto a $12 \%$ bis-tris polyacrylamide gel containing $0.1 \%$ sodium dodecylsulfate. Gels were transferred to PVDF membranes and blocked in PBS + 0.1\% Tween 20 (PBST) $+5 \%$ dry milk for $1 \mathrm{~h}$ at RT. Blots were incubated with rabbit $\alpha$-VAChT antibody 1:1000 (Life Technologies) at $4^{\circ} \mathrm{C}$ overnight. After $3 \times 10 \mathrm{~min}$ washes in PBST buffer, blots were incubated with anti-rabbit horseradish peroxidase secondary antibodies (Jackson ImmunoResearch) for $1 \mathrm{~h}$ at RT. Blots were washed three more times in PBST before the addition of Supersignal chemiluminescent substrate (Thermo Fisher Scientific) and imaging.

To analyze phospho-Ser40 TH levels, Western blot analysis was performed as above except that the striatum was dissected and then homogenized and spun at $20,000 \times g$ for $20 \mathrm{~min}$ at $4^{\circ} \mathrm{C}$. The supernatant was used to determine protein concentrations and the resulting blot was probed using rabbit $\alpha$-phosphoS40-TH 1:1000 (Millipore).

Histology. To analyze spine density and dendritic arborization, mice were euthanized and the brain immediately removed and stained with the FD Rapid Golgi Stain Kit according to the manufacturer's instructions (FD Neurotechnology). Briefly, brains were incubated in solutions $\mathrm{A}$ and $\mathrm{B}(1: 1)$ for $7 \mathrm{~d}$ in the dark at RT, changed to solution $\mathrm{C}$ for $4 \mathrm{~d}$ at $4^{\circ} \mathrm{C}$, and then rapidly frozen in isopentane and stored at $-80^{\circ} \mathrm{C}$. Golgistained brains were then sectioned at $100 \mu \mathrm{m}$ thickness and dehydrated with successive ethanol and xylene treatments. Slices were then mounted on slides and coverslipped with Permount (Sigma-Aldrich). Spines were imaged by bright-field microscopy (Olympus IX71 inverted microscope) with a $60 \times$ magnification oil objective (numerical aperture 1.65) and Rolera-XR camera at coordinates 1.5 to $0.15 \mathrm{AP}, 1.75$ to $1.0 \mathrm{ML}$, and -2.5 to $-3.5 \mathrm{DV}$ for dorsal striatum and 1.5 to $1.0 \mathrm{AP}, 1.0$ to $1.5 \mathrm{ML}$, and -4.25 to $-4.75 \mathrm{DV}$ for ventral striatum. Two independent researchers blind to genotype manually counted the spines. Dendrite length was measured using MetaMorph software (Olympus).

Electrophysiology. For whole-cell patch-clamp recording in striatal slices, male and female mice (6-8 weeks of age) were euthanized either before 11:00 A.M. (sleep cycle) or after 2:00 P.M. (waking cycle) and $300-\mu \mathrm{M}$-thick coronal slices were cut using a vibrating microtome (Leica Vibrotome 200C) with the tissue submerged in an ice-cold, sucrosebased solution containing the following (in $\mathrm{mm}$ ): $79 \mathrm{NaCl}, 23 \mathrm{NaHCO}_{3}$, 68 sucrose, 12 glucose, $1.1, \mathrm{NaH}_{2} \mathrm{PO}_{4}, 6 \mathrm{MgCl}_{2}$, and $0.5 \mathrm{CaCl}_{2}$. Slices were then allowed to recover at RT for a minimum of $1 \mathrm{~h}$ in oxygenated artificial CSF (ACSF) containing the following (in mM): $118 \mathrm{NaCl}, 3 \mathrm{KCl}$, $2.5 \mathrm{CaCl}_{2}-2 \mathrm{H} 2 \mathrm{O}, 1.5 \mathrm{MgSO}_{4}, 0.6 \mathrm{NaH}_{2} \mathrm{PO}_{4}, 25 \mathrm{NaHCO}_{3}$, and 10 glucose. Whole-cell patch-clamp recordings were performed using borosilicate pipettes (4-6 $\mathrm{M} \Omega$ resistance) filled with an internal solution containing the following (in mM): $135 \mathrm{~K}$-gluconate, $4 \mathrm{NaCl}, 2 \mathrm{MgCl}_{2}, 10$ HEPES, 0.2 EGTA, 2.5 ATP-Na, 0.2 GTP-Na, with or without $0.2 \%$ biocytin and $0.01 \%$ Alexa Dextran 488. Most recordings were performed without compensation; however, several cells were recorded first without compensation and then with whole-cell compensation and there was no difference in the results. Cells in which series resistance changed $>20 \%$ over the course of the recording were excluded from analysis. MSNs were identified by their size $(\sim 10-15 \mu \mathrm{m}$ diameter $)$, resting potential $\left(V_{\mathrm{r}}\right.$ between -70 and $-90 \mathrm{mV}$ ), low input resistance (between 50 and 200 $\mathrm{M} \Omega$ ), and regular (nonadapting) firing pattern in response to current injection.

For FSCV, evoked DA release from coronal sections of the striatum $(300 \mu \mathrm{m})$ was measured from male mice ( 8 to 24 weeks old) euthanized either before 11:00 A.M. (sleep cycle) or after 6:00 P.M. (waking cycle). Slices were allowed to recover for $1.5 \mathrm{~h}$ in oxygenated ASCF containing the following (in mM): $125 \mathrm{NaCl}, 2.5 \mathrm{KCl}, 26 \mathrm{NaHCO}_{3}, 2.4 \mathrm{CaCl}_{2}, 1.3$ $\mathrm{MgSO}_{4}, 0.3 \mathrm{KH}_{2} \mathrm{PO}_{4}, 10$ glucose) at $\mathrm{RT}$, placed in a recording chamber, and superfused $(1 \mathrm{ml} / \mathrm{min})$ with ACSF at $36^{\circ} \mathrm{C}$. Electrochemical recordings and electrical stimulation were performed as described previously (Zhang and Sulzer, 2003). Briefly, freshly cut carbon fiber electrodes $\sim 5$ $\mu \mathrm{m}$ in diameter were inserted into the dorsal striatum or nucleus accumbens shell or core at a location of $\sim 50 \mu \mathrm{m}$ into the slice. For FSCV, a triangular voltage wave $(-400$ to $+900 \mathrm{mV}$ at $280 \mathrm{~V} / \mathrm{s}$ versus $\mathrm{Ag} / \mathrm{AgCl})$ was applied to the electrode every $100 \mathrm{~ms}$ and current recorded using an Axopatch 200B amplifier (Axon), with a low-pass Bessel filter set at 10 $\mathrm{kHz}$, digitized at $25 \mathrm{kHz}$ (ITC-18 board; Instrutech). Slices were electrically stimulated every 2 min with either a single pulse, 2, pulses, 4 pulses, or 10 pulses using a bipolar stimulating electrode $\sim 100 \mu \mathrm{m}$ from the recording electrode. Background-subtracted cyclic voltammograms identified the released substance as DA. The DA oxidation current was converted to concentration based upon a calibration of $5 \mu \mathrm{M}$ DA in ACSF after the experiment.

Statistics. Unless otherwise noted, data represent the mean \pm SEM and were analyzed by Prism version 5 software (GraphPad). Automated Scholl 
analysis was performed with a combination of ImageJ, NeuronJ, Bonfire software, NeuronStudio, and MATLAB. The coefficient of error, a measure of sampling error, was calculated for each animal and group for each stereological analysis. Unless otherwise stated, statistical analysis consisted of a 2-way ANOVA with an $\alpha=0.05$ and a Bonferroni post hoc analysis. Asterisks indicate statistical significance in the post hoc analysis as follows: ${ }^{\star} p<0.05$, ${ }^{* *} p<0.01$, and ${ }^{* * *} p<0.001$.

\section{Results}

To better characterize the hyperlocomotor activity of the global VGLUT3 KO mice, we assessed ambulatory activity across the circadian cycle in a home cage environment (Fig. 1A). Compared with WT littermates, VGLUT3 KO mice showed a robust increase in total ambulations (peak of night 2; $237 \pm 35 \%$ ) during the waking cycle (nighttime), but no difference during the sleep cycle (daytime) (2-way ANOVA, $p=0.0002$ ). Because the motivating factors that underlie locomotor behavior in a home cage may differ from those engaged outside of the home cage, we also measured ambulatory activity in the open field for $7 \mathrm{~h}$ spanning the sleep-awake cycle (Fig. 1B). Locomotor activity after the daynight transition was also significantly greater compared with controls $(81.9 \pm 10.6 \%$ Student's $t$ test, $p=0.0083)$. Therefore, VGLUT3 KO mice show robust hyperlocomotor activity only during the waking state and this is not dependent on a home cage environment.

Hyperlocomotor activity is often accompanied by increased rearing behavior in rodents. However, the global VGLUT3 KO mice did not show a change in rearing at night despite being hyperactive (day 1: $58.7 \pm 11 \%$ increase in total ambulations, $p=$ 0.0073 ; day 2: $83.7 \pm 13.7 \%$ increase, $p=0.0079$; day 3: $67.2 \pm$ $29.2 \%$ increase, $p=0.0214)$. Interestingly, compared with the littermate control mice, KOs showed a decrease in rearing during the daytime, which continued to decrease on consecutive days $(37.1 \pm 8.1 \%$ decrease on day 3; Student's $t$ test $p=0.038$; Fig. $1 C)$. The data therefore indicate a mechanism present in the VGLUT3 KO mice that suppresses ambulatory-related rearing.

Hyperlocomotor activity in mice is often causally linked to an increase in striatal DA signaling (Gras et al., 2008; Bello et al., 2011; Brown et al., 2011). We therefore measured evoked DA release in striatal slices taken from VGLUT3 KO and WT littermates at night and during the day using FSCV. Relative to control littermates, VGLUT3 KO mice released significantly more DA in response to single-pulse stimulation of the dorsal striatum when measured at night $(50 \pm 17 \%, p=0.0006$; Fig. $1 D)$. DA release was also significantly elevated in the nucleus accumbens shell $(48 \pm 10 \%, p=0.0031)$ and core $(45 \pm 16 \%, p=0.0115)$. In contrast, no significant difference in DA release was detected in the striatum measured during the day. Therefore, evoked DA release in the $\mathrm{KO}$ corresponds to changes in locomotor activity.

The increased release of DA may reflect an increase in vesicular content or an effect on the modulation of release at the DA terminal. Because cytoplasmic DA levels are kept extremely low through tight regulation, measurement of tissue content can be used to assess vesicular DA levels. We therefore measured the content of DA in striatal tissue by HPLC at night and during the day. At night, DA levels were indeed significantly higher in tissue from VGLUT3 KO mice compared with WT littermate controls $(16.8 \pm 5.5 \%, p=0.0005$; Fig. $1 E)$. Levels of the metabolites DOPAC and 3-MT did not differ and levels of norepinephrine, epinephrine, 5-HT, and the 5-HT metabolites 5-HIAA and HVA were also unchanged. As expected, there was no significant difference in DA levels from whole striatal tissue collected during the daytime (Fig. 1E). Because increased vesicular DA content can result from an increase in DA synthesis, we measured levels of the active form of the rate-limiting enzyme for synthesis, phosphorylated tyrosine hydroyxlase (pTH) using Western blot. When tissue was harvested at night, pTH levels were significantly increased compared with littermate controls (92.8 $\pm 24.3 \%$, 2 -way ANOVA, $p=0.001$; Fig. $1 F)$. No significant difference in pTH levels were detected between genotypes when whole striatal tissue was collected during the day. Together, the data indicate that loss of VGLUT3 leads to an increase in striatal DA synthesis, packaging, and release that depends on the circadian cycle, pointing to a previously unappreciated role for the transporter in regulating striatal DA transmission.

\section{Properties of MSNs in the VGLUT3 KO mouse}

Midbrain DA terminals form symmetric synapses on the dendritic spines and shafts of MSNs, where they modulate corticostriatal and thalamostriatal glutamatergic signaling and plasticity, including MSN spine density (Centonze et al., 2001; Cazorla et al., 2012; Fasano et al., 2013; Ishikawa et al., 2013). When harvested at night, spine densities in the dorsal and ventral striatum were significantly increased in VGLUT3 KO animals (dorsal striatum, $48.2 \pm 1.5 \%, p=0.001$; ventral striatum, $41.1 \pm 3.8 \%$, $p=0.0019$, Student's $t$ test; Fig. $2 A$ ). In contrast, MSN spine densities measured during the day did not differ between genotypes. To assess whether there were additional changes in the structure of MSN dendrites, we performed Scholl analysis on the slices harvested at night. We observed no difference in the number of Scholl intersections, branch points, or termination points counted in either the dorsal or ventral striatum (Fig. 2B). Last, we investigated whether the transient increase in spines at night generated new functional contacts by performing whole-cell patchclamp recordings in the dorsal striatum of $\mathrm{KO}$ and WT littermates. No differences were detected in the resting potential, input resistance, firing rate or action potential properties (Fig. $2 C, D)$. We also did not detect differences in MSN properties between the two genotypes when cells were recorded during the day (data not shown). Measures of spontaneous activity can indicate altered connectivity, but no change in this parameter was observed across the circadian cycle (Fig. 2E). Therefore, MSN spine density in VGLUT3 KO mice is highly dynamic across the circadian cycle and correlates with changes in the level of DA release. Consistent with their transient nature, electrophysiological measurements indicate that the additional spines observed at night in the $\mathrm{KO}$ are functionally immature.

\section{Cholinergic-neuron-specific deletion of VGLUT3}

Striatal cholinergic interneurons have a profound influence on the striatal microcircuitry, including the regulation of DA signaling, and can potentially act through the release of ACh or glutamate. A previous report demonstrated that abolishing only ACh release from CINs through the selective deletion of VAChT in the striatum does not affect locomotor activity (Guzman et al., 2011). To determine whether glutamate signaling by CINs has a role, we used our newly generated Cre-lox conditional $\mathrm{KO}$ mice (Vglut ${ }^{\mathrm{fl} / \mathrm{fl}}$; Fig. 3A; Peirs et al., 2015). As a control, we also deleted VGLUT3 globally in this line by crossing the Vglut $3^{\mathrm{fl} / \mathrm{fl}}$ mice to the germline deleter strain Rosa26-Cre and refer to these mice as $V_{\text {glut }} 3^{\Delta / \Delta}$ (Fig. 3A-E). Western blot analyses of brain tissue showed normal levels of the transporter in Vglut $3^{\mathrm{f} / \mathrm{fl}}$ mice and an absence of VGLUT3 in the germline-deleted mice (Peirs et al., 2015). Immunohistochemical analysis from the $\operatorname{Vglut}^{\Delta / \Delta}$ mice also showed a complete loss of the transporter in brain (Fig. 3C) and peripheral neurons known to express it (Peirs et al., 2015). 
A

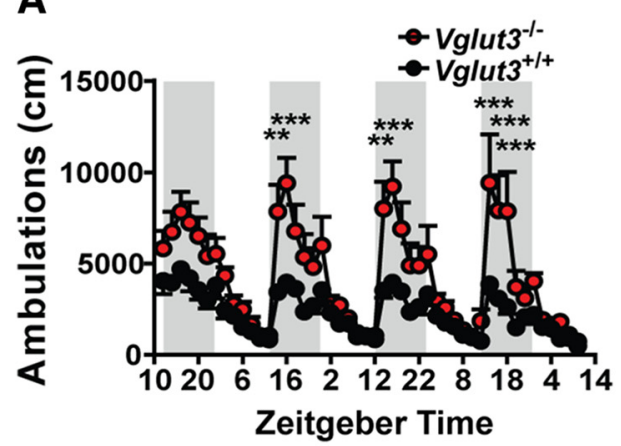

C
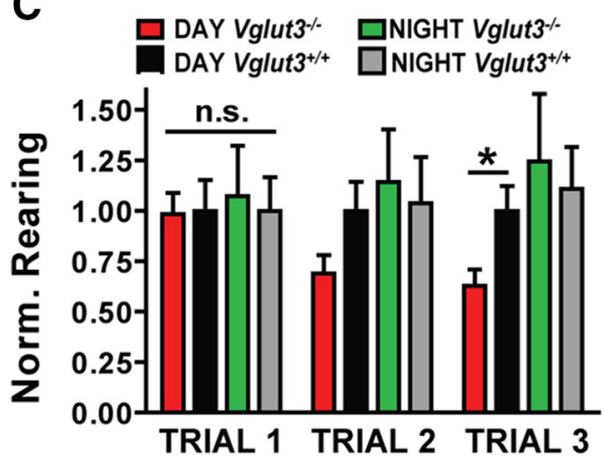

D

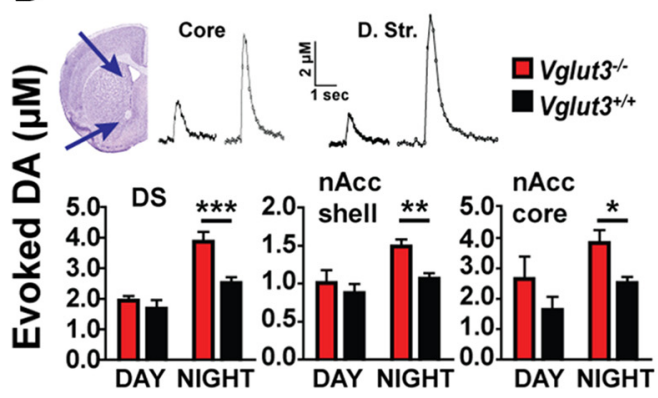

F

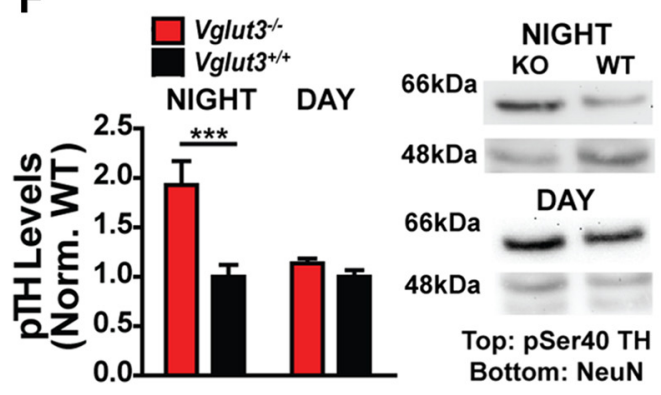

B
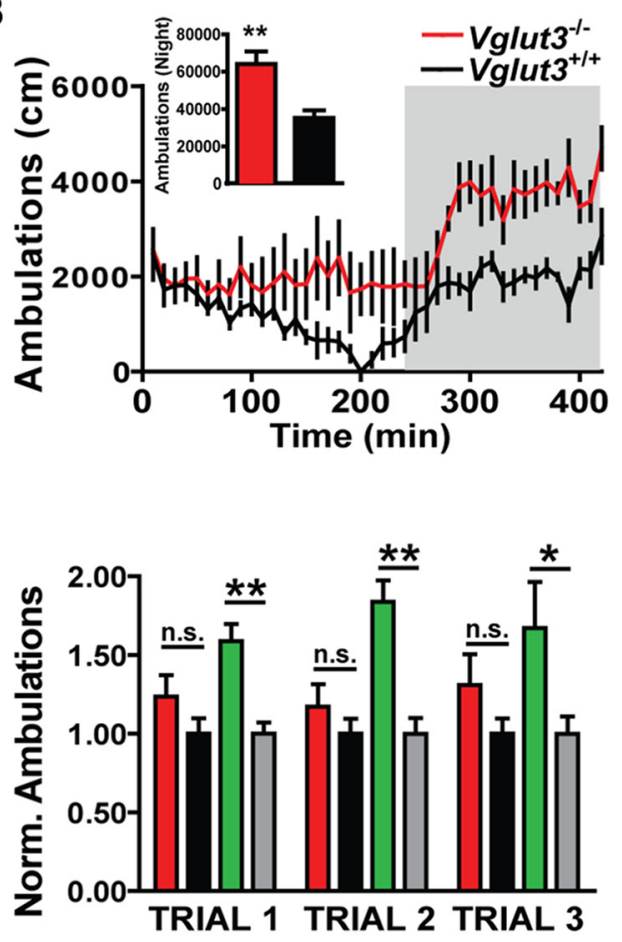

E

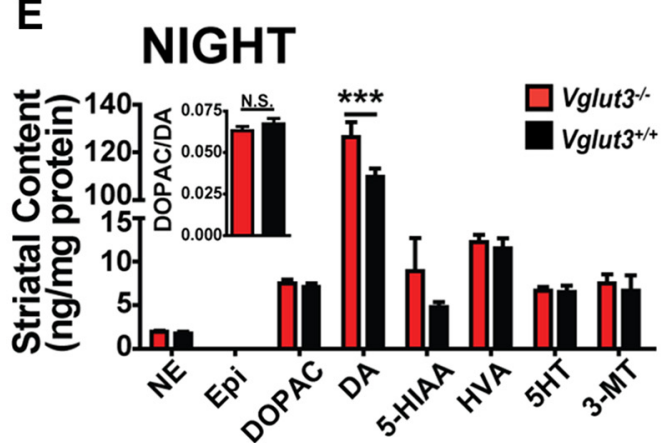

DAY

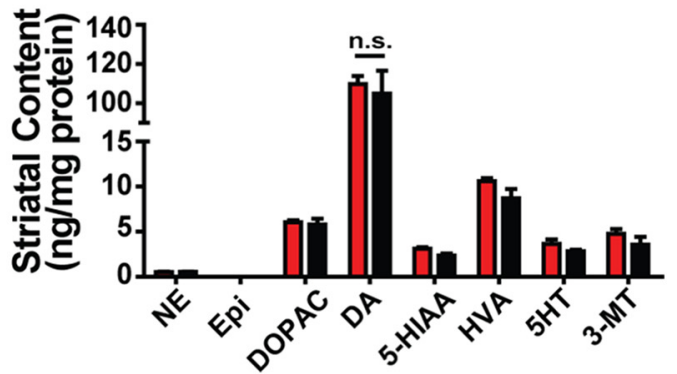

Figure 1. VGLUT3 K0 mice display circadian-dependent hyperdopaminergia. A, Ambulatory activity of VGLUT3 KO (red) and WT littermates (black) in a home cage environment ( $n=8$ mice per condition). Dark regions indicate the nighttime/awake cycle. $\boldsymbol{B}$, Locomotor activity in open field for VGLUT3 KO (red) and WT (black) mice ( $n=6$ mice per genotype). Total ambulations measured across the sleep/wake cycle (dark region of graph indicates the awake cycle). Total ambulations during the awake cycle (insert). Data were analyzed by Student's $t$ test. C, Rearing behavior of VGLUT3 KO (day: red; night: green) and WT littermates (day: black; night: gray) in an open field (left). Ambulatory behavior of VGLUT3 KO (day: red; night: green) and WT littermates (day: black; night: gray) measured in conjunction with rearing behavior (right). Data were normalized to WT activity and analyzed by Student's $t$ test ( $n=9$ mice and 6 mice for the day and night, respectively). D, FSCV of evoked DA release in dorsal striatum, nucleus accumbens (nAcc) core and shell. Representative traces of DA release from WT (closed circles) and VGLUT3 KO littermates (open circles) in the nAcc core and dorsal striatum (top); average concentration of DA released in VGLUT3 KO (red) and WT (black) littermates ( $n=9$ male mice per genotype; bottom). $\boldsymbol{E}$, HPLC of biogenic amines (pmol/mg tissue) in VGLUT3 KO (red) and WT (black) littermates (top); ratio of DOPAC and DA (insert; $n=12 \mathrm{female}$ and 7 male mice for KOs and 9 female and 7 male mice for WTs). HPLC of striatum harvested during the day (bottom; $n=5$ mice per genotype). $\boldsymbol{F}$, Ratio of striatal pTH to NeuN in VGLUT3 KO (red) and WT littermates (black; $n=4$ female and 2 male mice per group) in a Western blot analysis (left). VGLUT3 immunoreactivity in striatal tissue harvested during the sleep cycle (DAY) and waking cycle (NIGHT; right). A pTH band appears at $\sim 62 \mathrm{kDa}$ and the control marker NeuN appears at $\sim 48 \mathrm{kDa}$. ( $A-F)$ Data are displayed as the mean $\pm S E M$ and unless otherwise noted were analyzed by 2-way ANOVA genotype $\times$ day with a Bonferroni post hoc test. n.s., Not significant; ${ }^{*} p<0.05,{ }^{* *} p<0.01$, ${ }^{* * *} p<0.001$. 
A
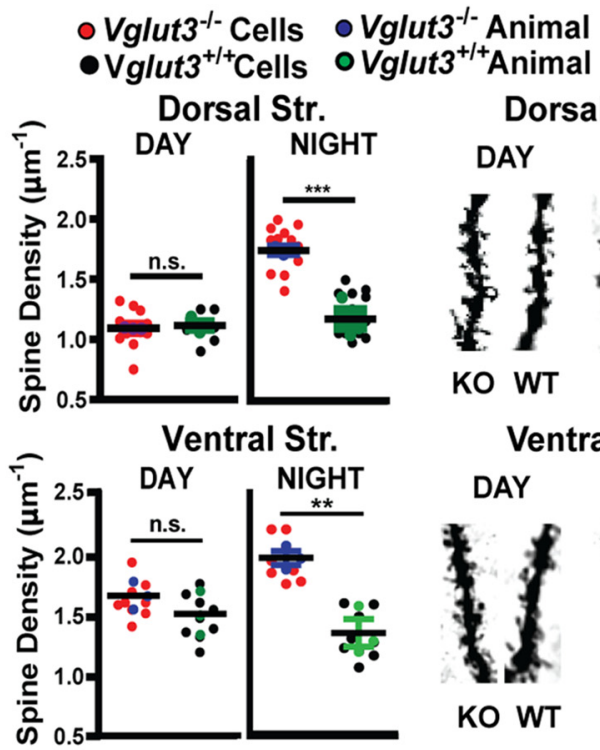

Dorsal Str.

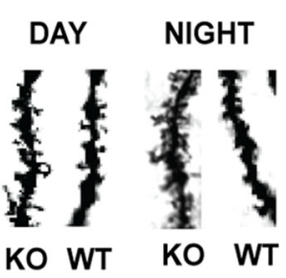

Ventral Str.

DAY NIGHT

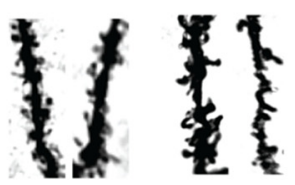

KO WT KO WT

B

Dorsal Str.
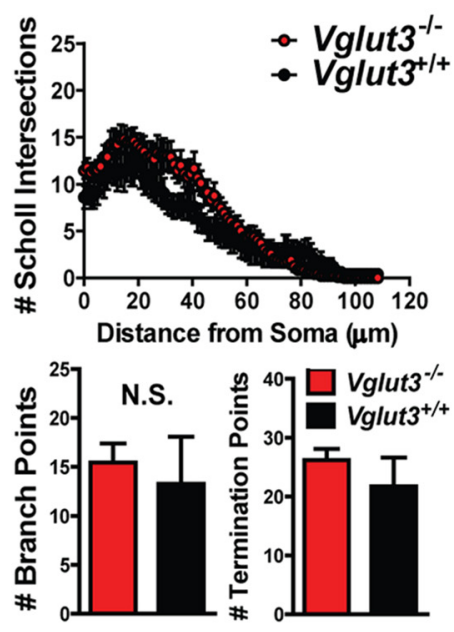

Ventral Str.
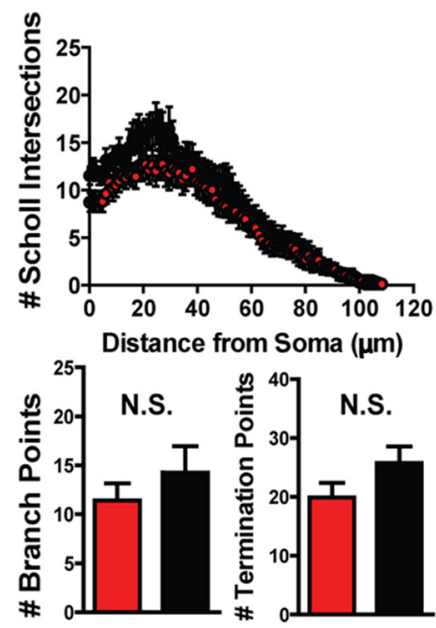

C

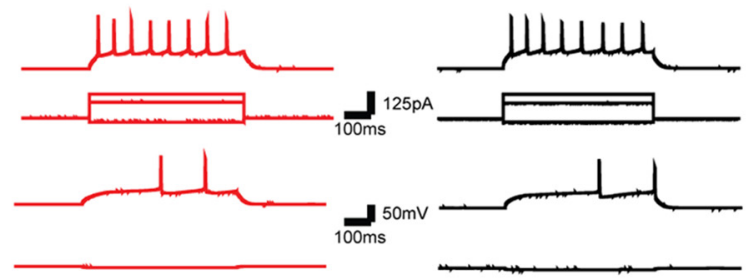

D

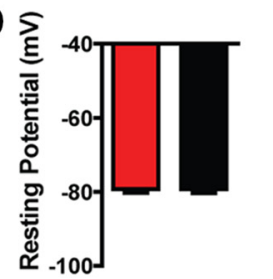

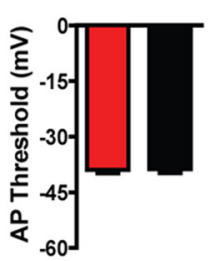

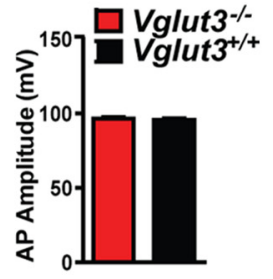

E

DAY

NIGHT
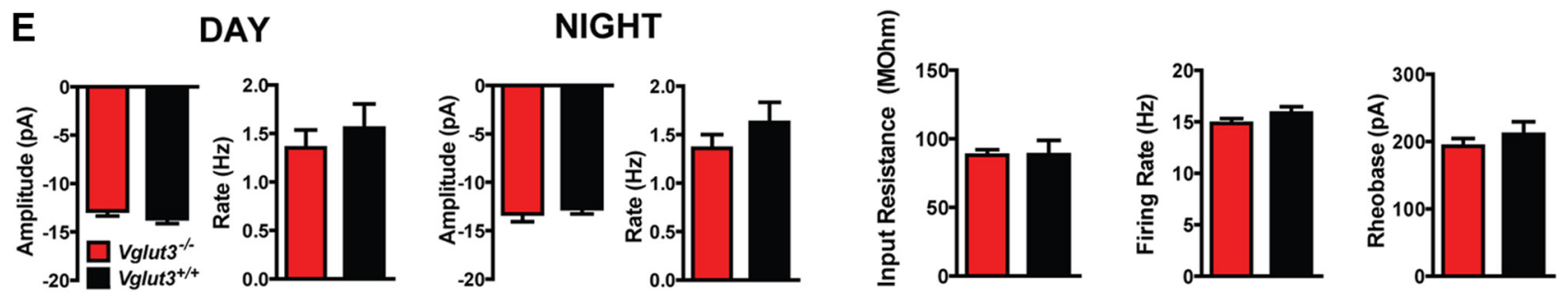

Figure 2. Morphological and electrophysiological properties of MSNs. A, Average spine density of MSNs located in the dorsal striatum from VGLUT3 KO (blue) or WT (green) littermates during the day (top left) and night (top middle). Average spine density of MSNs in ventral striatum of KO (blue) or WT (green) littermates during the day and night (bottom left, bottom-middle). Spine density of each cell measured in the KO (red) and WT (black) animals. Black bars indicate the mean and colored bars indicate the SEM for all animals of a particular condition (left; $12-17$ cells and $n=3-4$ male mice per condition). Representative Golgi-stained images from KO and WT littermates for each condition are shown (top right, bottom right). $\boldsymbol{B}$, Scholl analysis of MSNs from dorsal and ventral striatum from the same animals used in $A$. Number of dendritic intersections with Scholl rings from MSNs located in the dorsal striatum are shown at top left. Number of branch points and terminal points from dorsal MSNs are shown at bottom left. Scholl intersections from ventral striatum MSNs are shown at top right. Number of branch and terminal points in ventral MSNs are shown at bottom right. C, Representative voltage responses to current injections in VGLUT3 KO mice (red; left) and WT littermates (black; right). D, MSN electrophysiological properties from K0 and WT littermates recorded during the nighttime ( $n=14-18$ cells from 4 female and 1 male mice for each condition). $E$, Spontaneous EPSC amplitudes from MSNs during the daytime and nighttime (left) and frequency of EPSCS from both times of day (right; $n=9$ - 11 cells from 5 female and 1 male mice per condition). Data are presented as the mean \pm SEM and were analyzed by 2-way ANOVA genotype $\times$ day with a Bonferroni post hoc test $(\boldsymbol{A}, \boldsymbol{B})$ or a Student's $t$ test $(\boldsymbol{D}, \boldsymbol{E})$. N.S., Not significant.

Finally, consistent with the original global deletion, VGLUT3 ${ }^{\Delta / \Delta}$ mice do not startle to a loud sound (Fig. 3E; Seal et al., 2008).

Previous data suggest that cholinergic forebrain neurons, but not cholinergic cortical interneurons or hindbrain neurons, express VGLUT3 (Gritti et al., 2006; Nickerson et al., 2006; Wang and Morales, 2009). To confirm this expression pattern, we crossed our BAC transgenic Vglut $3^{\mathrm{Cre} /+}$ mice (Grimes et al., 2011) to the lsl-tdTomato reporter line (Madisen et al., 2010) and then costained brain slices with an antibody to the cholinergic cell marker ChAT. In this mouse line, tomato expression reflects all cells that have ever expressed Cre (VGLUT3). We observed colocalization of the tomato and ChAT in striatal cholinergic interneurons, as well as cranial nerves III, IV, and VI and a subset of basal forebrain cholinergic neurons (Fig. $4 C-F$ ), but the tomato reporter was not observed in hindbrain cholinergic nuclei (LDT and PPTg; Fig. 4, $A, B$, respectively) or in cortical cholinergic interneurons.

To delete VGLUT3 from cholinergic interneurons, we crossed the Vglut ${ }^{\mathrm{fl} / \mathrm{fl}}$ line to mice that express Cre under the control of Chat gene regulatory elements [Chat-Cre $(\mathrm{G})$ mice]. As expected, VGLUT3 immunoreactivity was not detected in striatal cholinergic interneurons of $\mathrm{Vglut}^{\mathrm{f} / / \mathrm{f}} ;{ }^{\text {; Chat }}{ }^{\mathrm{Cre}(\mathrm{G}) /+}$ mice (Fig. $5 \mathrm{~A}$ ). To determine whether loss of VGLUT3 from cholinergic neurons is sufficient to produce the hyperlocomotor behavior, we measured ambulatory activity continuously for $48 \mathrm{~h}$ (Fig. 5B). Contrary to the prevailing hypothesis, $\operatorname{Vglut}^{\mathrm{fl} / \mathrm{f}} ; \mathrm{Chat}^{\mathrm{Cre}(\mathrm{G}) /+}$ mice showed normal levels of locomotor activity across the circadian cycle. Because the gene locus of Chat also encodes the gene for Vacht, the use of this BAC transgenic line may have introduced increased copies of the Vacht allele, as has been observed in other 
BAC transgenic lines constructed using this locus (Nagy and Aubert, 2012; Kolisnyk et al., 2013; Crittenden et al., 2014). In this case, elevated levels of VAChT may have raised vesicular ACh content and thus suppressed the normally elevated locomotor activity of the $\mathrm{KO}$ during the waking cycle. To determine whether VAChT expression is increased in the BAC transgenic line, we performed Western blot analysis of striatal synaptosomes taken from Chat ${ }^{\mathrm{Cre}(\mathrm{G}) /+}$ and WT littermates. VAChT levels in the Chat ${ }^{\mathrm{Cre}(\mathrm{G}) /+}$ mice were $\sim 2$-fold higher $(90 \pm 32 \%$ increase, Student's $t$ test, $p=0.022$; Fig. $5 C$ ), similar to other BAC transgenic lines constructed using the Chat locus. To determine whether this increased VAChT expression masked the hyperlocomotor activity of global VGLUT3 KO mice, we

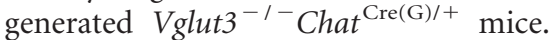
These mice demonstrated robust hyperlocomotor activity that did not differ statistically from the global KO alone (Fig. 5D), thus indicating that the 2-fold higher expression of VAChT did not suppress the hyperlocomotor activity.

To avoid the potential for confounds introduced by the ChAT-Cre $(\mathrm{G})$ line, we used the knock-in ChAT-IRES-Cre line in all future experiments. In these mice, Cre was knocked into the 3'UTR of the Chat locus, avoiding effects on ChAT or VAChT levels (Rossi et al., 2011). Immunohistochemical analysis of striatal slices from Vglut $^{\mathrm{fl} / \mathrm{fl}}$;Chat ${ }^{\mathrm{IRESCre} /+}$ mice confirmed deletion of VGLUT3 in CINs (Fig. 6A). Tested over 48 h, Vglut $3^{\mathrm{fl} / \mathrm{fl}}$; Chat ${ }^{\mathrm{IRESCre} /+}$ mice also showed normal ambulatory activity over the entire circadian cycle (Fig. 6B), again indicating that loss of VGLUT3 in cholinergic neurons does not affect locomotor activity.

The relationship between CINmediated signaling and evoked DA release is complex (Zhou et al., 2002; Cachope et al., 2012) and may include a role for CINs in gating the frequency dependence of DA release (Zhang and Sulzer, 2004; Threlfell et al., 2012). We therefore also measured evoked DA release in the dorsal striatum of Vglut $^{\mathrm{fl} / \mathrm{fl}}$;Chat ${ }^{\mathrm{IRESCre} /+}$ mice using FSCV. DA release evoked by a single pulse stimulation was similar between $\operatorname{Vglut} 3^{\mathrm{fl} / \mathrm{fl}}$; Chat ${ }^{\mathrm{IRESCre} /+}$ and littermate controls, suggesting that DA release from the readily releasable pool of vesicles is not altered by the loss of VGLUT3 (Fig. 6C, left). To determine whether DA released from the total pool of vesicles was altered, we applied 70 $\mathrm{mm} \mathrm{KCl}$ to the slice (Gubernator et al., 2009; Rodriguez et al., 2013). We also did not detect a difference in DA release under these conditions (Fig. 6C, right). Finally, we measured the level of DA release evoked by trains of either 4 or 10 pulse stimulations performed at either 20 or $100 \mathrm{~Hz}$. DA release was again similar between genotypes under these conditions (Fig. 6D). Therefore,

1. WT

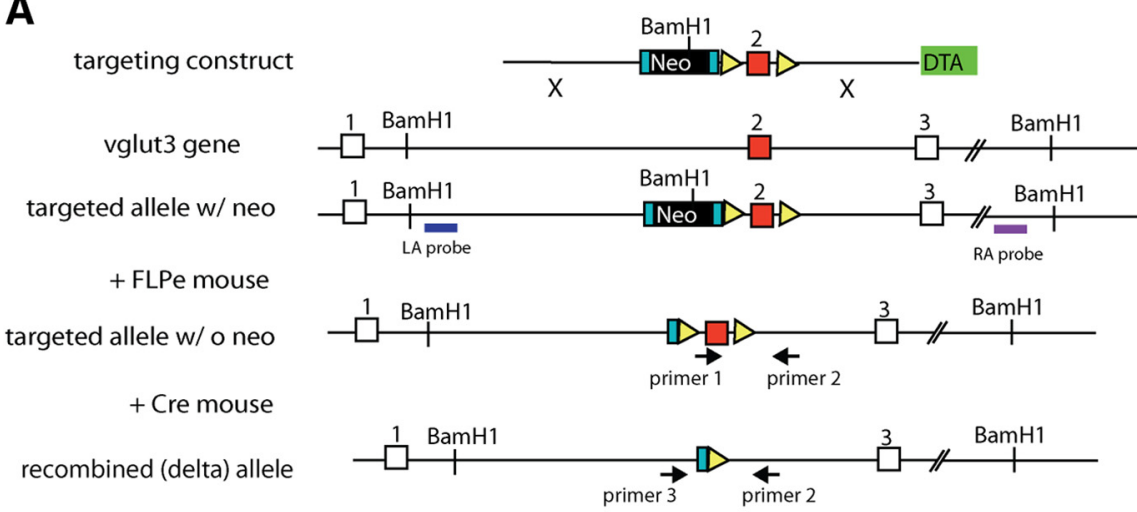

\section{B Southern Blot C Immunohistochemistry}

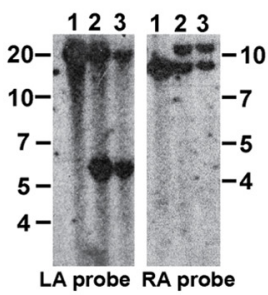

2. Properly targeted clone \#1

3. Properly targeted clone \#2

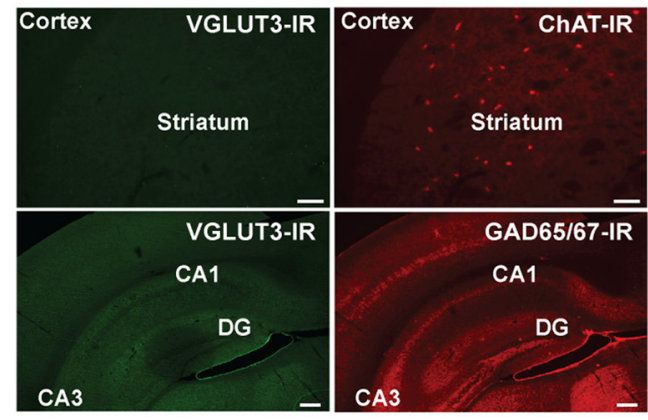

\section{E Acoustic Startle}

$\begin{array}{lllll}2 & 3 & 4 & 5 & 6\end{array}$
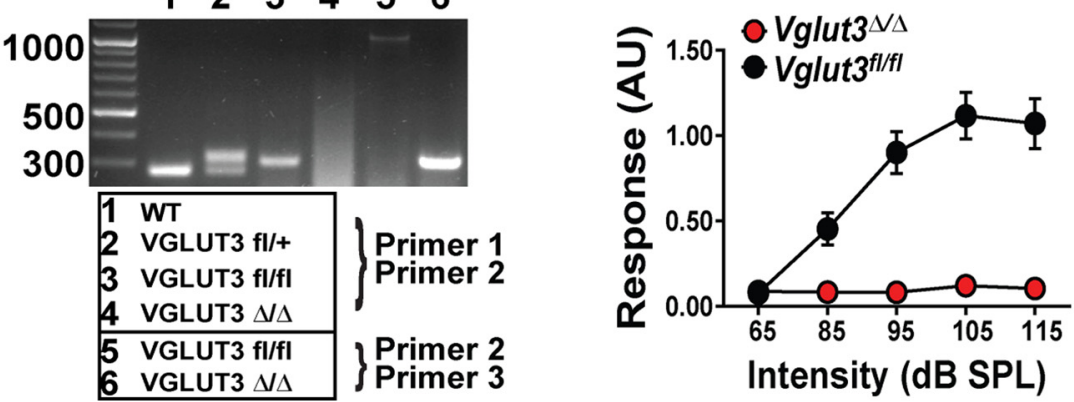

Figure 3. Generation and characterization of VGLUT3 conditional KO line. $A$, Construction of the BAC vector. The FRT flanked TK-neo gene was deleted by crossing founders to the Rosa $26^{\mathrm{Flp}}$. Exposure to Cre recombinase excises exon 2. B, Southern blot analysis of ES cell clones show proper targeting of the left and right arms in clones 2 and 3 . C, $\mathrm{HC}$ of $\mathrm{Vglut} 3^{\Delta / \Delta}$ mice depicting loss of VGLUT3 expression from nuclei known to express the transporter. 10X images taken from striatal slice stained for VGLUT3 (left; (right; $594 \mathrm{~nm}$; bottom). Scale bar, $50 \mu \mathrm{m}$ for all images. D, PCR-based genotyping using primers 1 and 2 to detect the floxed allele and primers 2 and 3 to detect the recombined allele. $E$, Acoustic startle is robust in Vglut $3^{\text {fl/fl }}$ (black) and absent in Vglut ${ }^{\Delta / \Delta}$ mice (red). Data are the mean \pm SEM for $n=2$ female and 4 male mice per genotype.

loss of VGLUT3 from CINs does not alter evoked DA release in the dorsal striatum. Consistent with measurements of locomotor activity and DA release, HPLC analysis of whole striatal DA content measured in mice that were euthanized at night was also similar between genotypes (Fig. 6E). Finally, in agreement with the lack of enhanced DA release, MSN spine densities measured in both dorsal striatum and ventral striatum of Vglut $^{\mathrm{fl} / \mathrm{fl}}$;Chat ${ }^{\text {IRESCre/+ }}$ mice were similar to Vglut ${ }^{\mathrm{fl} / \mathrm{fl}}$ mice when the animals were euthanized at night (Fig. $6 F$ ).

To determine whether the altered rearing behavior observed in the Vglut $3^{-/-}$mice was due to a loss of VGLUT3 specifically from cholinergic neurons, we measured rearing in the Vglut $^{\mathrm{fl} / \mathrm{fl}}$;Chat $\mathrm{IRESCre}^{\mathrm{IR}}$ and littermate mice across $3 \mathrm{~d}$ (Fig. $6 \mathrm{G}$ ). 
A
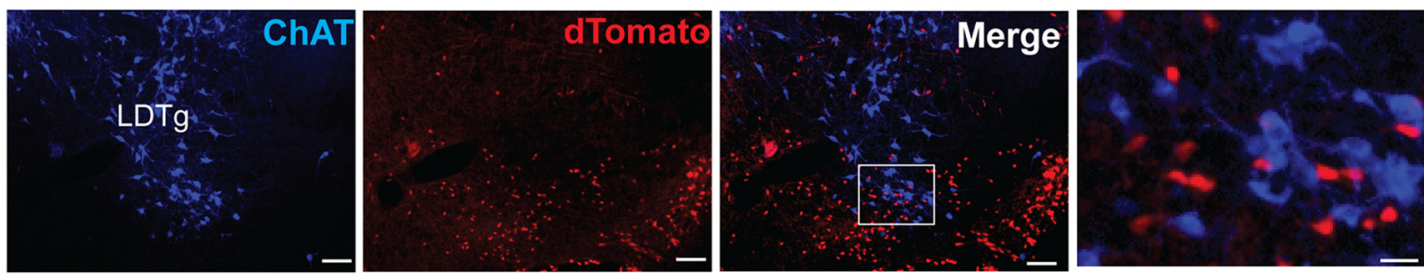

B
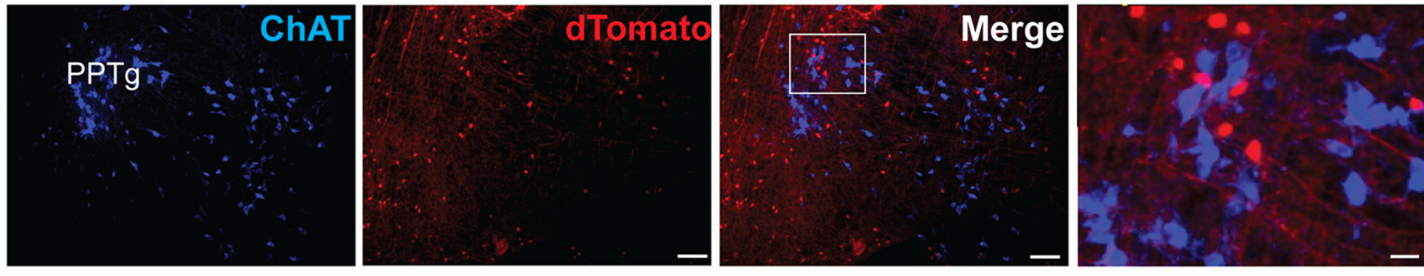

C
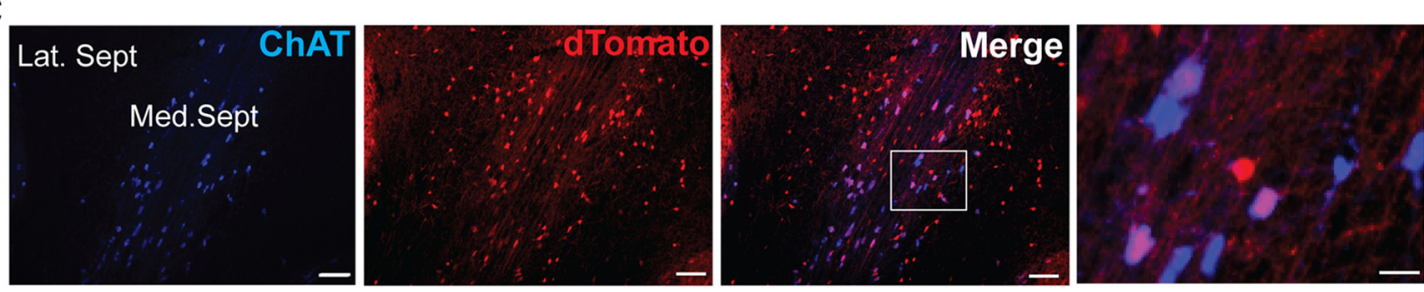

D
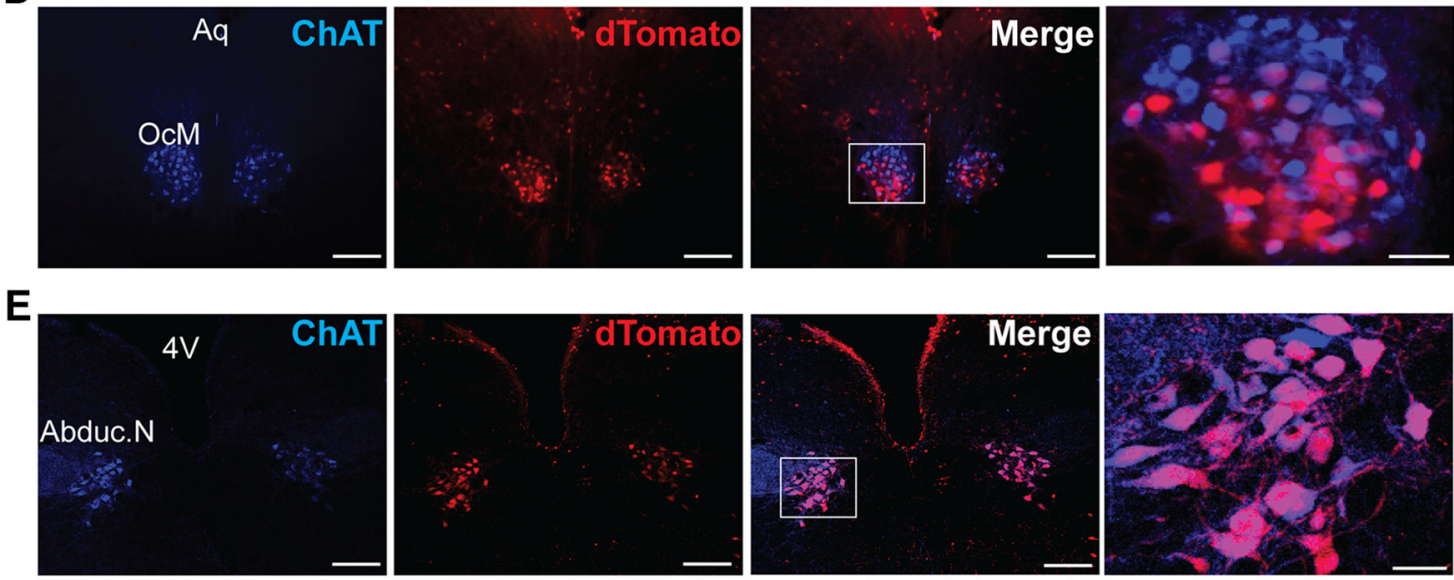

$\mathbf{F}$
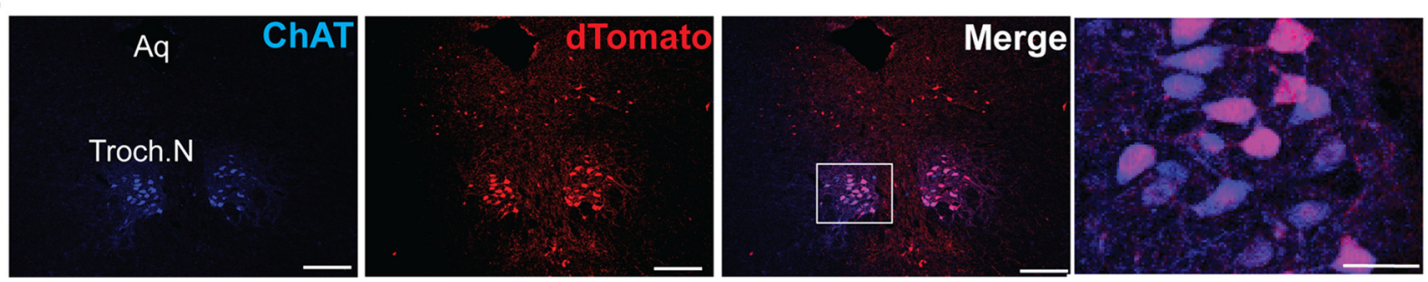

Figure 4. Expression of VGLUT3 in cholinergic nuclei. Shown are $10 \times$ images $(\boldsymbol{A}-\boldsymbol{C})$ and $20 \times$ images $(\boldsymbol{D}-\boldsymbol{F})$ from Isl-tdTomato;VGLUT3 ${ }^{\text {Cre }}$ mice costained for ChAT (blue) reveals overlap of cholinergic and Tomato ${ }^{+}$(VGLUT3) populations. A, Laterodorsal tegmental nucleus (LDTg). B, Pedunculopontine tegmental nucleus (PPTg). C, Medial septum (Med. Sept.) and lateral septum (Lat. Sept.). D, 0culomotor nerve (OcM/III) and aqueduct (Aq).E, Abducens nerve (Aduc.N/VI) and fourth ventricle (4V). $\boldsymbol{F}$, Trochlear nerve (Troch.N/IV). Scale bar, $50 \mu \mathrm{m}$ for 10 and $20 \times$ images (left three images). Scale bar, $12 \mu \mathrm{m}$ for high-magnification images (right).

Compared with the littermate control mice, rearing episodes were significantly attenuated on the third day $(42.0 \pm 8.7 \%$ decrease, 2 -way ANOVA, $p=0.0116$ ). Therefore, although loss of VGLUT3 from cholinergic neurons does not produce hyperlocomotor behavior, it does influence rearing behavior.

The dorsal striatum is important for the processing of sensorimotor information and alterations in circuitry can influence behaviors such as the ability of a brief noise, or prepulse, to in- hibit acoustic-induced startle responses. Ablation of CINs was shown to reduce the prepulse inhibition of startle (PPI; Laplante et al., 2011), but the deletion of VAChT in the striatum does not alter PPI (Guzman et al., 2011), thus pointing to a potential role for CIN-mediated glutamate signaling in regulating this behavior. We therefore used the Vglut $3^{\mathrm{fl} / \mathrm{fl}}$;Chat ${ }^{\mathrm{IRESCre} /+}$ mice to test whether PPI is altered by the loss of VGLUT3-mediated glutamate signaling. Compared with WT littermates, Vglut ${ }^{\mathrm{fl} / \mathrm{fl}}$; 
A

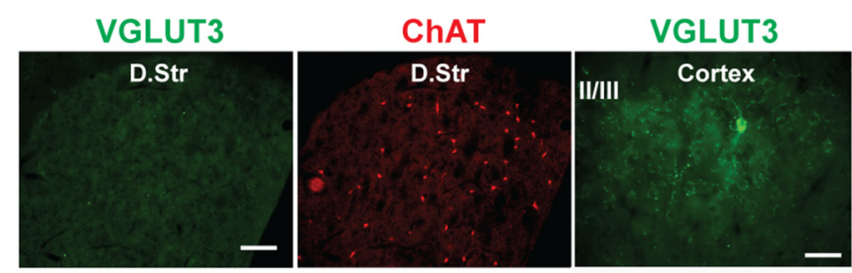

C

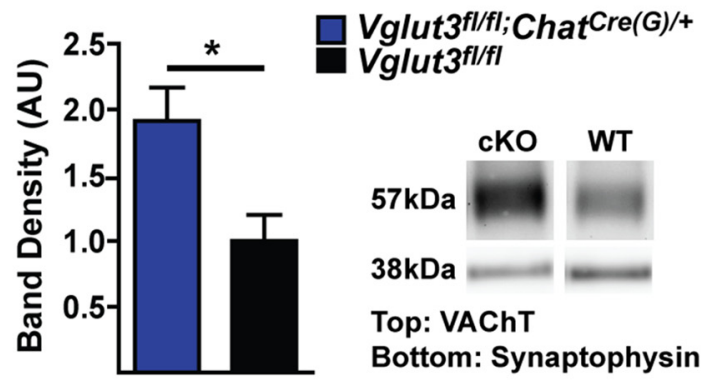

B

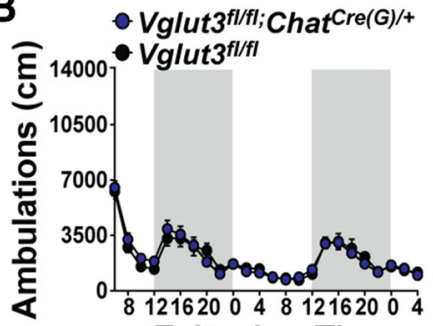

Zeitgeber Time

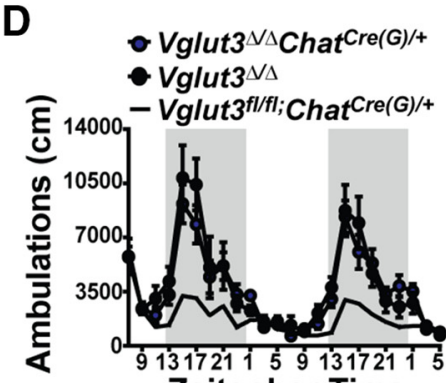

Zeitgeber Time

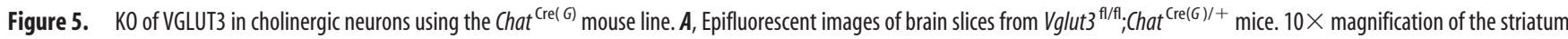
immunostained for VGLUT3 ( $488 \mathrm{~nm}$; left) and ChAT (594 nm; left-middle). Scale bar, $50 \mu \mathrm{m}$. A $40 \times$ image of the cortex immunostained for VGLUT3 is shown (right). Scale bar, $20 \mu \mathrm{m}$. $\boldsymbol{B}$, Ambulatory activity of Vglut $3^{\mathrm{fl} / \mathrm{fl}}$; Chat ${ }^{\mathrm{Cre}(G) /+}$ and Vglut $3^{\mathrm{fl} / \mathrm{fl}}$ littermates ( $n=14$ male and 11 female mice per genotype). Dark regions indicate the awake cycle. $C$, Western blot of striatal lysates from Vglut $3^{\mathrm{fl} / \mathrm{fl} \text {; } C \text { hat }}{ }^{\mathrm{Cre}(G) /+}$ and Vglut3 ${ }^{\mathrm{fl} / \mathrm{fl}}$ littermates probed for VAChT. Relative levels of VAChT in Vglut3 ${ }^{\text {fl/fl. }}$; Chat ${ }^{\text {Cre(G)/+ }}$ mice (blue) compared with Vglut3 ${ }^{\text {fl/fl }}$ (black) controls (left). Immunoreactivity to VAChT appears at $\sim 57 \mathrm{kDa}$ (top right); loading control synaptophysin at $\sim 37 \mathrm{kDa}$ (bottom right). Data are presented as the mean $\pm \mathrm{SEM}$ ( $n=8$ mice per genotype) normalized to loading controls and were analyzed by Student's $t$ test. $D$, Ambulatory activity of Vglut3 ${ }^{\Delta / \Delta}$; Chat ${ }^{\text {Cre }(G) /+}$ mice $\left(n=4\right.$ female and 8 male mice) and VGLUT3 ${ }^{\Delta / \Delta}$ littermates $(n=4$ female and 6 male mice). Dark regions indicate the waking cycle and the dotted line indicates the mean activity of $\mathrm{Vglut} 3^{\mathrm{fl} / \text { fl. }}$; $C$ hat ${ }^{\mathrm{Cre}(G) /+}$ mice taken from $\boldsymbol{B}$. Data are presented as the mean $\pm \mathrm{SEM}$ and were analyzed by 2-way ANOVA genotype $\times$ day with a Bonferroni post hoc test $(\boldsymbol{B}, \boldsymbol{D}) .{ }^{*} p<0.05$.

Chat ${ }^{\mathrm{IRESCre} /+}$ mice showed significantly larger startle amplitudes after the prepulse (slope Vglut ${ }^{\mathrm{fl} / \mathrm{fl}} ;$ Chat $^{\text {IRESCre/+ }}=2.25 \pm 0.39$, slope $\mathrm{WT}=3.31 \pm 0.36$; linear regression analysis, $p=0.0477$; Fig. 7A), indicating impaired PPI. Baseline acoustic startle amplitudes were not different between the two genotypes. We also tested the Vglut $3^{\mathrm{fl} / \mathrm{fl}}$;Chat ${ }^{\mathrm{Cre}(\mathrm{G}) /+}$, which have increased levels of VAChT and potentially more ACh release. Interestingly, PPI in these mice was not significantly different from in the controls (Fig. $7 B$ ), suggesting that CIN-mediated signaling carried by either glutamate or ACh is sufficient to maintain normal PPI.

\section{Loss of VGLUT3 ameliorates motor symptoms in a} Parkinson's disease model

Parkinson's disease is a progressive neurodegenerative disorder that results in large part from a dramatic loss of nigrostriatal DA neurons and can be modeled in mice by the chemical lesioning of striatal DA terminals with the toxin 6-OHDA (Evetts et al., 1970; Ng et al., 1971; Steece-Collier et al., 2002; Grealish et al., 2008). We hypothesized that the increased striatal DA release in VGLUT3 KO mice would compensate for the reduced nigrostriatal DA in a model of Parkinson's disease, thereby improving motor function. Unilateral DA depletion was achieved by injecting $6 \mu \mathrm{g}$ of 6-OHDA into the dorsomedial striatum and motor behavior monitored 1-3 weeks later. To determine the extent of DA lesioning, TH immunoreactivity was quantified every $\sim 300$ $\mu \mathrm{m}$ across the dorsal striatum in the rostral-caudal direction (Fig. 8A). The percentage decrease in ipsilateral TH immunoreactivity (compared with contralateral) did not differ between genotypes $(67.4 \pm 8.0 \%$ for KO and $74.9 \pm 6.3 \%$ for WT; Student's $t$ test, $p=0.49$ ). We additionally analyzed DA levels by HPLC using a 1.6-mm-diameter tissue punch taken from the dorsomedial striatum. Again, no difference was observed between $\mathrm{KO}$ and
WT littermates $(98.4 \pm 0.3 \%$ reduction for $\mathrm{KO}$ mice, $99.6 \pm$ $0.1 \%$ reduction for WT mice).

To assess motor function, we measured spontaneous rotations in the open field and front paw contacts made during rearing in a cylinder (Fig. 8B). Spontaneous rotations toward the injected or ipsilateral (left) side are enhanced by unilateral depletion of nigrostriatal DA (Von Voigtlander and Moore, 1973). Before injection of 6-OHDA, the number of CW (right) and CCW (left) rotations made over a $15 \mathrm{~min}$ period was the same in VGLUT3 KO and WT littermates at night and during the day. After unilateral DA depletion, the WT mice showed a significant increase in spontaneous rotations to the ipsilateral (CCW; left) side when measured during the day $(78.5 \pm 4.1 \%$, 2-way ANOVA, $p=0.0002)$ and a significant increase at night $(70.4 \pm$ $7.4 \%, p=0.0087$; Fig. $8 B$, top). Remarkably, with the same degree of DA depletion, turning behavior in the VGLUT3 KO was completely unaffected across the circadian cycle.

Paw preference in the cylinder assay is also sensitive to unilateral DA depletion, showing a dramatic bias toward reaching with the ipsilateral paw (Glajch et al., 2012). Before injection of 6-OHDA, VGLUT3 KO and WT littermates showed equal contralateral and ipsilateral, weight-bearing paw contacts during rearing (Fig. $8 A$, bottom). After injection, the WT mice demonstrated a significant increase in ipsilateral paw reaching both during the day $(70 \pm 7 \%$, 2-way ANOVA, $p=0.0008)$ and at night ( $69 \pm 7 \%, p=0.0007)$. In contrast, VGLUT3 KO mice showed no paw preference at either time of day (day: ipsilateral: $54.9 \pm$ 1.8\%; contralateral: $45.1 \pm 1.8 \% ; p=0.19$; night: ipsilateral: $53.6 \pm 2.4 \%$; contralateral: $46.5 \pm 2.3 \%$; $p=0.29$ ). In summary, our experiment showed that, despite undergoing a similar degree of DA depletion after 6-OHDA treatment, VGLUT3 KO mice 
A
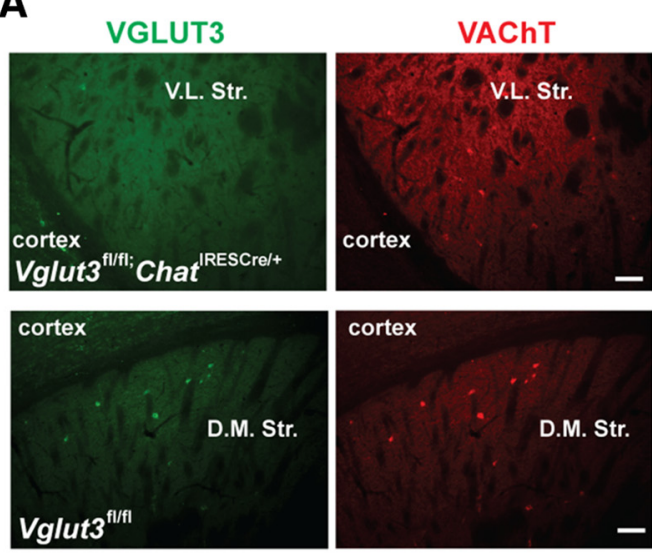

C

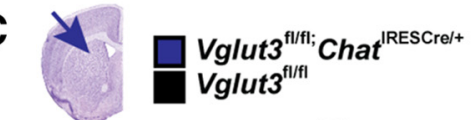
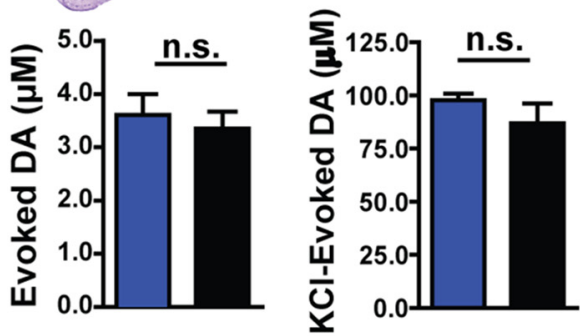

B

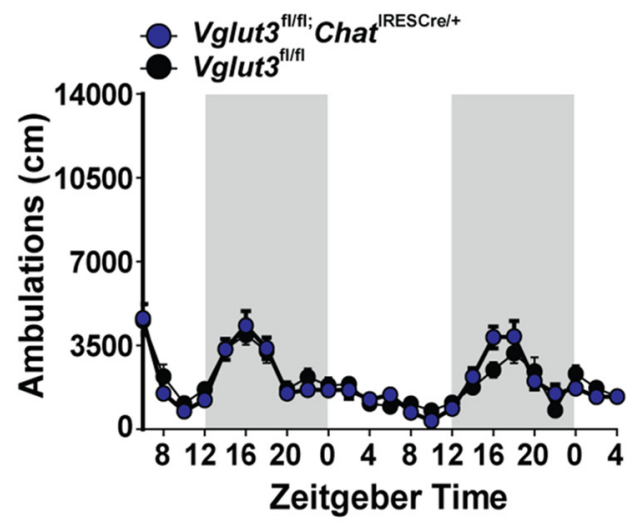

D
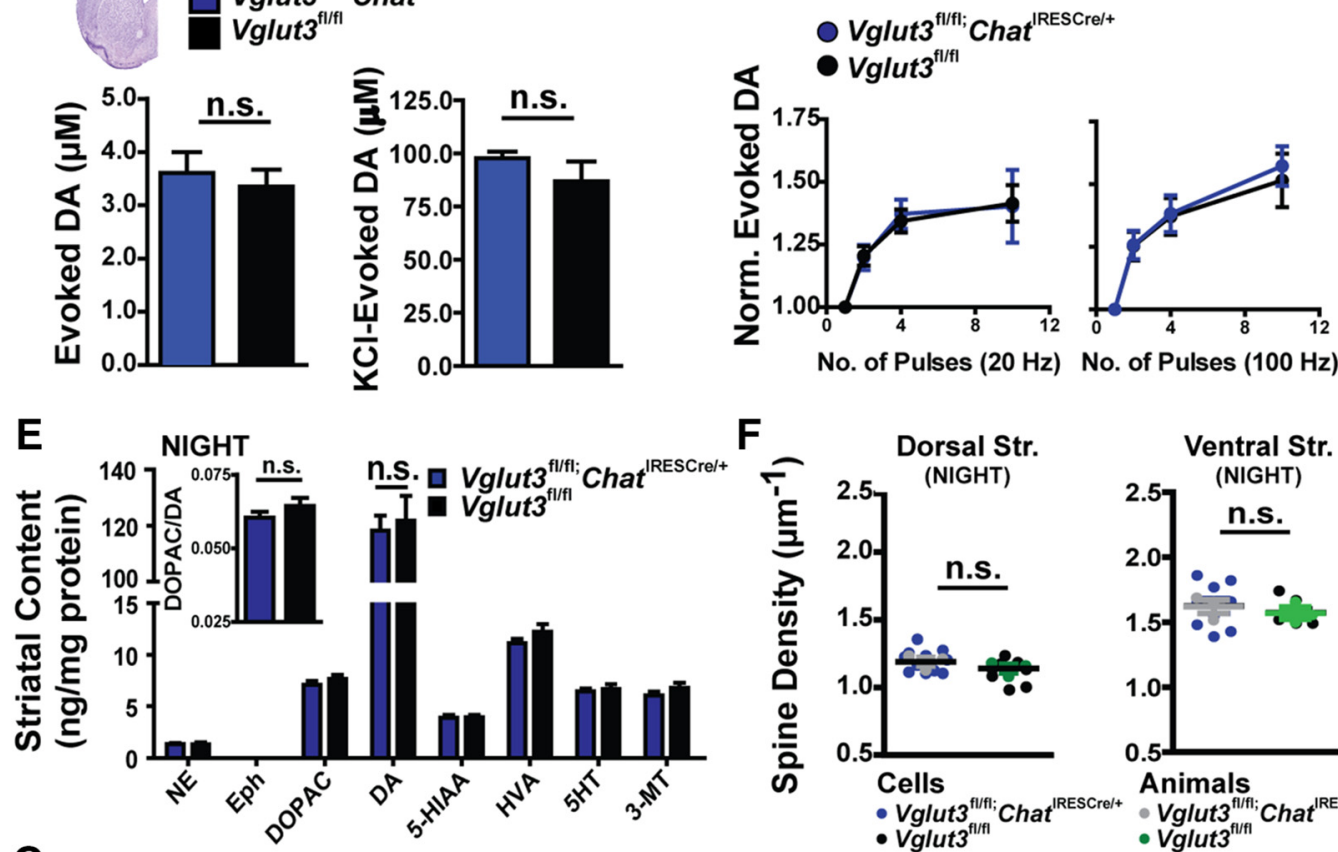

F
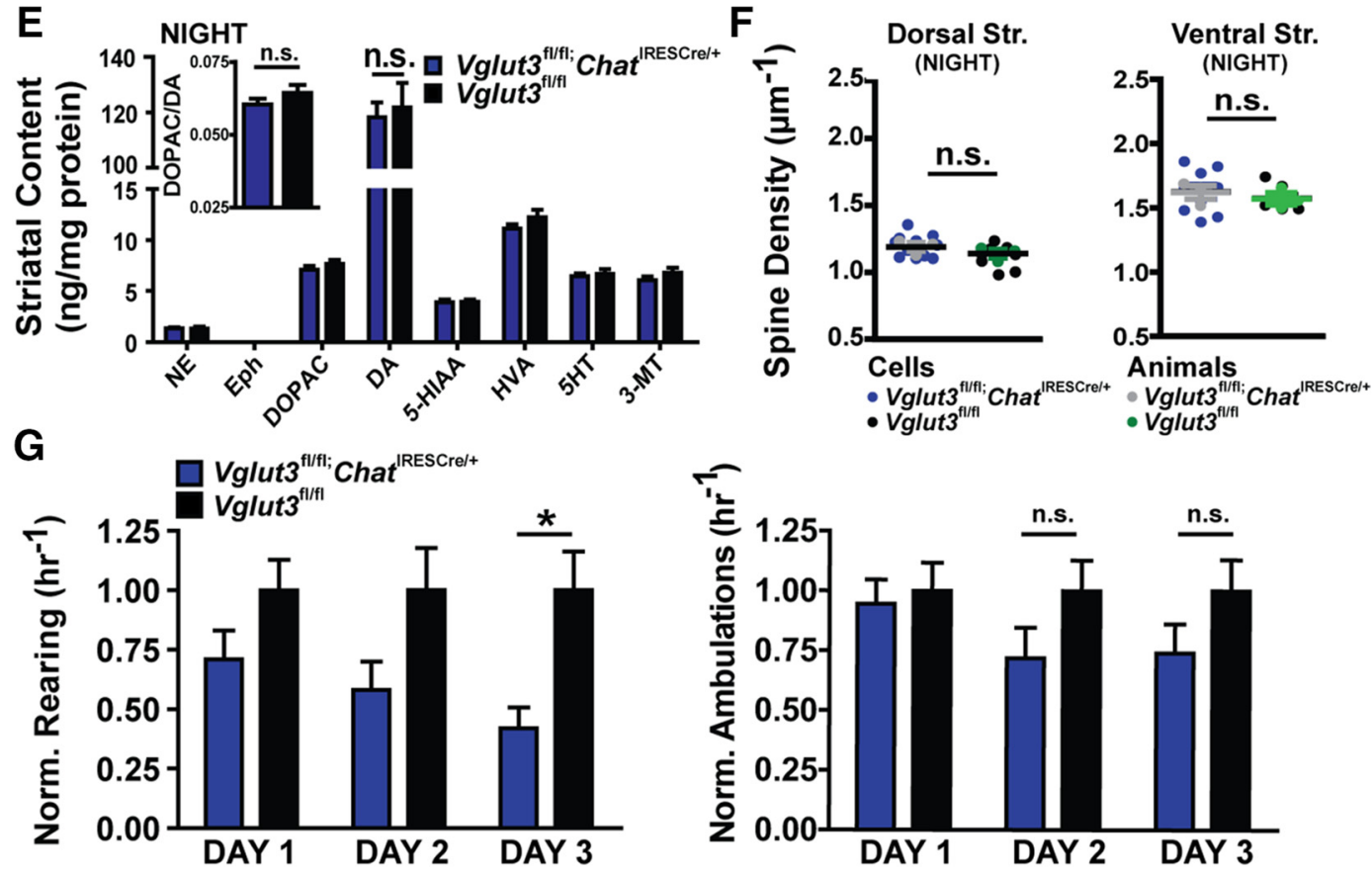

Figure 6. Locomotor activity and striatal DA signaling in the $\mathrm{Vglut} 3^{\mathrm{fl} / \mathrm{fl}}$;Chat ${ }^{\mathrm{IRESCr} /+}$ mouse. $A$, IHC images taken at $10 \times$ magnification of the striatum and surrounding cortical regions

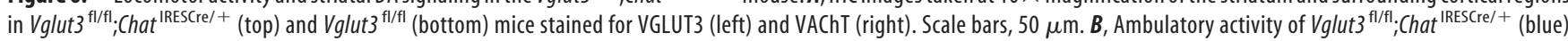
mice and Vglut ${ }^{\mathrm{fl} / \mathrm{fl}}$ (black) littermates ( $n=14$ and 12 mice, respectively). Dark regions indicate the waking cycle. $\boldsymbol{C}$, FSCV of evoked DA release measured in dorsal striatum of

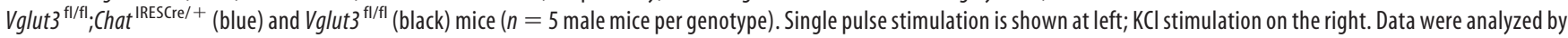
Student's $t$ test. $D, D$ A release from 2,4 , and 10 stimulation pulses was normalized to release from a single pulse. Stimulation pulses at $20 \mathrm{~Hz}$ (left) and $100 \mathrm{~Hz}$ frequency (right; $n=11-23$ cells and 5 male mice per genotype). E, HPLC for biogenic amines (pmol/mg tissue) from striatum of Vglut ${ }^{\text {fl/fl }}$;Chat ${ }^{\text {IRESCre/+ }}$ (b/ue) and Vglut ${ }^{\text {fl/fl }}$ (black) littermates; ratio of DOPAC and

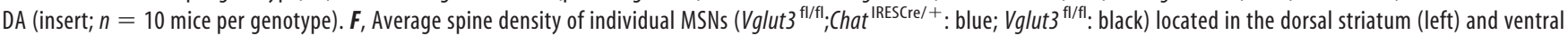
striatum (right) of Vglut $3^{\mathrm{fl} / \mathrm{fl}}$; Chat ${ }^{\text {IRESCre/+ }}$ (gray) and Vglut3 ${ }^{\mathrm{fl} / \mathrm{fl}}$ (green) mice. Data were analyzed by Student's $t$ test (12-13 cells from $n=3$ mice per genotype). $\mathbf{G}$, Rearing behavior

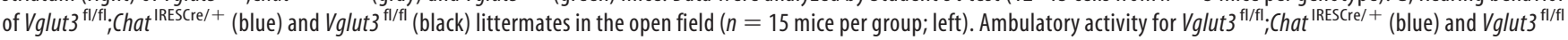
(black) littermates in an open field ( $n=14$ and 12 mice per genotype; right). $\boldsymbol{B}-\boldsymbol{G}$, Data are presented mean \pm SEM and were analyzed by 2 -way ANOVA genotype $\times$ time with a Bonferroni post hoc test. n.s., Not significant; ${ }^{*} p<0.05$. 
A
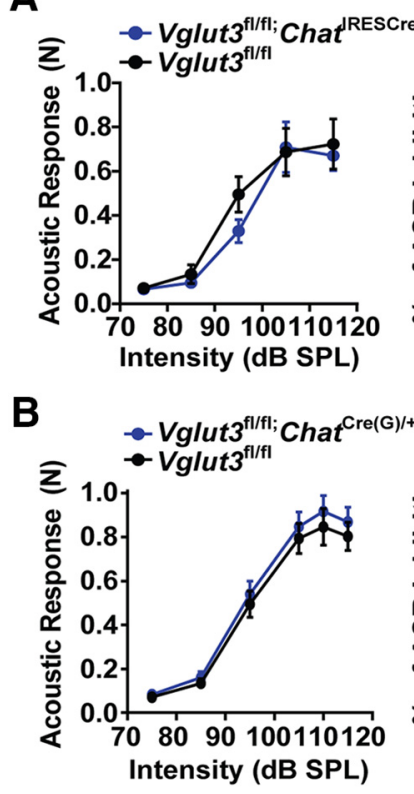
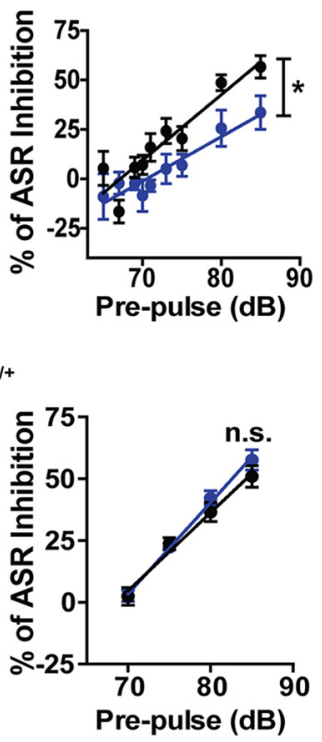

Figure 7. Prepulse inhibition. $\boldsymbol{A}$, Acoustic startle response to increasing noise intensity in

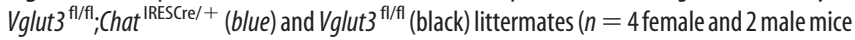
per genotype). Startle response to sounds from 75 to $115 \mathrm{~dB}$ SPL (500 ms each; left). Startle response to $115 \mathrm{~dB} S P L$ noise exposures after a brief prepulse noise exposure ranging from 65 to $85 \mathrm{~dB}$ SPL (right). $\boldsymbol{B}$, Same as in $\boldsymbol{A}$ except with Vglut ${ }^{\mathrm{fl} / \mathrm{fl}}$; (hat $^{\mathrm{Cre}(\mathrm{G}) /+}$ (blue) and Vglut ${ }^{\mathrm{fl} / \mathrm{fl}}$ (black) littermates. Data are the mean \pm SEM and were analyzed by linear regression analysis comparing slopes between genotypes. n.s., Not significant.

exhibited normal motor behavior in contrast to the WT control mice, which showed the typical motor deficits.

Because anti-cholinergics have been shown to have therapeutic value for Parkinson's disease, we investigated whether deletion of VGLUT3 from cholinergic neurons contributes to the improved motor function after unilateral striatal DA depletion. One week after injection of 6-OHDA, rotational behavior was measured in the Vglut $3^{\mathrm{fl} / \mathrm{fl}}$; Chat ${ }^{\mathrm{IRESCre} /+}$ mice and Vglut $3^{\mathrm{fl} / \mathrm{fl}}$ littermates (Fig. 8C, left). Both genotypes showed a significant increase in spontaneous ipsilateral rotations in the open field compared with before lesioning (CCW turning $71.7 \pm 13.3 \%$, 2-way ANOVA, $p=0.045$; and $73.7 \pm 8.9 \%, p=0.0243$ for Vglut $^{\mathrm{fl} / \mathrm{fl}}$;Chat ${ }^{\mathrm{IRESCre} /+}$ and Vglut $3^{\mathrm{fl} / \mathrm{fl}}$ littermates, respectively). Likewise, weight-bearing paw contacts in a cylinder were significantly biased toward the ipsilateral paw in both sets of mice $(76.0 \pm 10.1 \%, 2$-way ANOVA, $p=0.001$, and $68.0 \pm 5.1 \%, p=$ 0.0059 , for Vglut $3^{\mathrm{fl} / \mathrm{fl}}$;Chat ${ }^{\text {IRESCre/+ }}$ and Vglut ${ }^{\mathrm{fl} / \mathrm{fl}}$ littermates, respectively; Fig. $8 C$, right). Therefore, deletion of VGLUT3 in CINs does not ameliorate the motor deficits caused by DA depletion. The improved motor function of the global VGLUT3 KO mice is likely due to the upregulation of the midbrain DA system, which does not occur in the conditional KO.

Global loss of VGLUT3 prevents L-dopa-induced dyskinesias L-dopa is the principal treatment strategy for Parkinson's disease. Administration of the precursor for DA synthesis alleviates motor dysfunction by restoring levels of the monoamine. However, long-term administration of the drug often results in hyperkinetic, involuntary movements known as LIDs. Mechanisms underlying this basal-ganglia-dependent behavior are unknown. To determine whether VGLUT3 has a role in the development of LID, we assessed dyskinetic behavior in VGLUT3 KO and WT littermates. We first lesioned the median forebrain bundle with

6-OHDA and then administered daily injections of 1,2 , or 3 $\mathrm{mg} / \mathrm{kg}$ L-dopa (see timeline in Fig. 9A). The extent of lesioning was determined by counting the total number of $\mathrm{TH}^{+}$neurons in the substantia nigra pars compacta using the optical fractionator (StereoInvestigator; MBF Bioscience). No difference was observed between the VGLUT3 KOs $\left(93.3 \pm 1.5 \%\right.$; percent $\mathrm{TH}^{+}$ neuron loss compared with intact side) and their WT littermates $(96.0 \pm 1.5 \%)$. Daily administration of low dose $(1 \mathrm{mg} / \mathrm{kg})$ L-dopa for 1 week resulted in the emergence of low-level LID behavior in both genotypes (Fig. 9B). In the second week of drug treatment, L-dopa was administered daily at a higher dose (2 $\mathrm{mg} / \mathrm{kg}$ ) and, at this dose, a significant difference in severity of LID between genotypes began to emerge. Mean LID severity scores were significantly less in KO mice than WTs at peak dose 20 and $40 \mathrm{~min}$ after injection. In the third and fourth weeks of drug treatment, the daily dose of L-dopa was further increased to 3 $\mathrm{mg} / \mathrm{kg}$ with or without a 2 -week drug-free washout period, respectively. The severity of LID continued to be significantly attenuated in the VGLUT3 KOs compared with WT controls at 20 and $40 \mathrm{~min}$ after injection of L-dopa (Fig. 9B). The difference in LID severity between the genotypes was maintained when data were analyzed for median and maximum LID score across dose and time (Fig. 9C,D, respectively; median LID score: $F_{(1,15)}=$ 18.03, $p=0.0001$; maximum LID score: $F_{(1,15)}=7.383$, $p=0.016)$ Therefore, in addition to ameliorating the motor symptoms of nigrostriatal DA depletion, loss of VGLUT3 also markedly attenuates the development of LIDs.

The ablation of cholinergic interneurons has also been demonstrated to ameliorate the severity of LID behaviors (Won et al., 2014). To assess whether loss of the glutamate release mediated by CINs is sufficient to attenuate LID, we repeated the experiment with the Vglut $3^{\mathrm{fl} / \mathrm{fl}}$;Chat ${ }^{\mathrm{IRESCre} /+}$ mice (Fig. 9E). Although not statistically significant, we did observe a strong trend of the Vglut $^{\mathrm{fl} / \mathrm{fl}}$;Chat ${ }^{\mathrm{IRESCre} /+}$ mice to show less LID than their control littermates, indicating there may be some contribution from the loss of VGLUT3 in CINs.

\section{Discussion}

Our present work shows that VGLUT3 regulates the basal ganglia, including the striatum, through multiple mechanisms. The global $\mathrm{KO}$ mice are significantly hyperlocomotive during their waking cycle and show a concomitant increase in the synthesis, packaging, and release of DA in both the ventral and dorsal striatum (Table 1). The increase in locomotor activity is consistent with increased DA synthesis and release, but the basis for the circadian dependence of the phenotype is less clear. Locomotor activity and extracellular DA levels normally fluctuate in a circadian-dependent manner, with higher extracellular levels of the transmitter occurring in the striatum during the waking cycle. However, the mechanism does not depend on the synthesis of additional DA, but rather on changes in the clearance rate set by the abundance of DA transporter on the plasma membrane (Ferris et al., 2014).

Mouse mutants that show a circadian-dependent change in locomotor activity typically involve genes that regulate the circadian cycle directly, such as Per1, Per2, Clock, and NR1D1 (McClung 2013). Indeed, studies have begun to focus on the relationship between circadian regulation of the midbrain DA system and mood disorders such as mania or attention deficithyperactivity disorder (ADHD). For example, a mutation of the Clock gene $($ Clock $\Delta 19)$ in mice produces circadian-dependent hyperlocomotion resembling mania that correlates with increased DA neuron activity and pTH levels (McClung et al., 
A

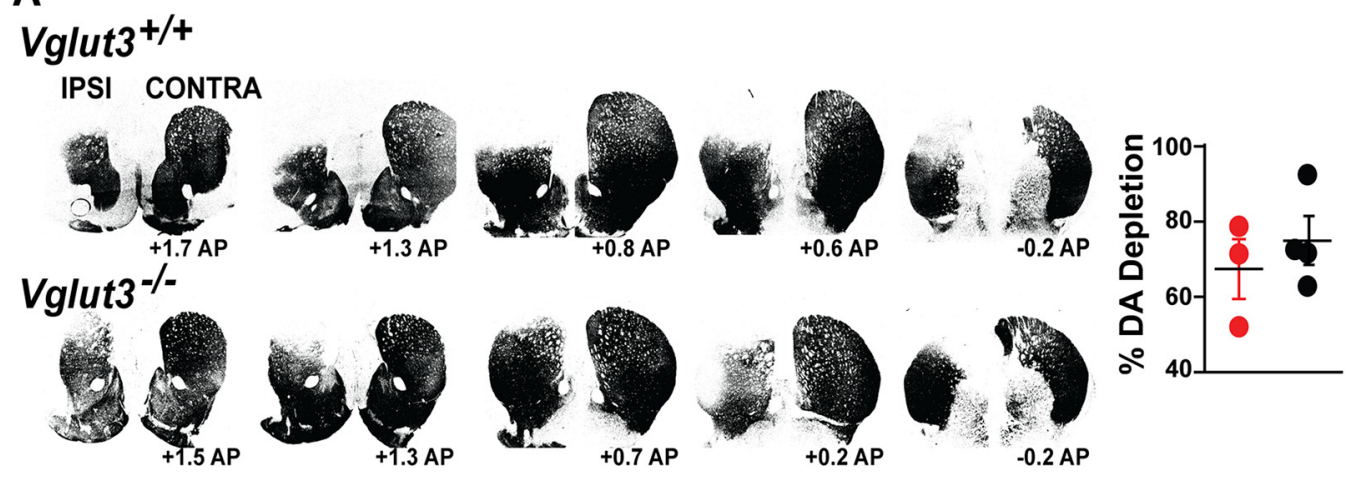

B

Spontaneous Rotations

Vglut $3^{-\%}$

Vglut $3^{+/+} \quad \mathbf{N}$ Vglut $3^{+/+}$
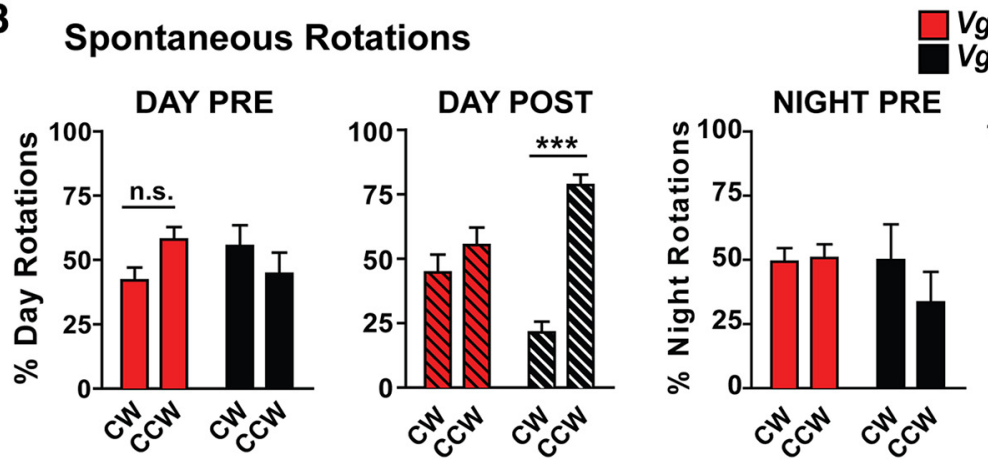

Cylinder Paw Reaches

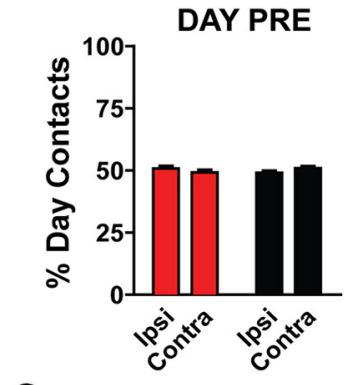

C
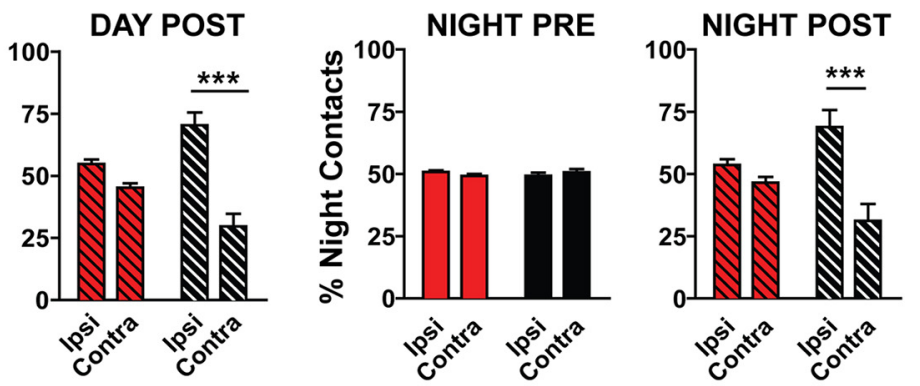

Vglut $3^{\mathrm{fl} / f \mathrm{l} ;}$ Chat ${ }^{\mathrm{RESCre} /+}$

Vglut $^{\mathrm{fl} / \mathrm{f}}$

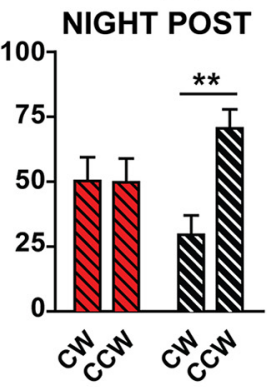

\section{Spontaneous Rotations}

PRE

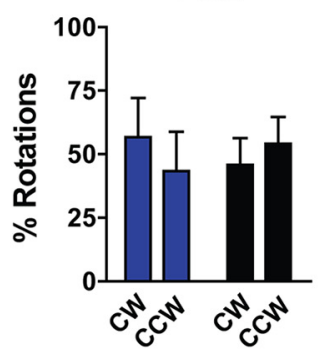

POST

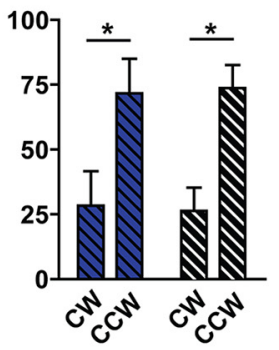

Cylinder Paw Reaches

PRE

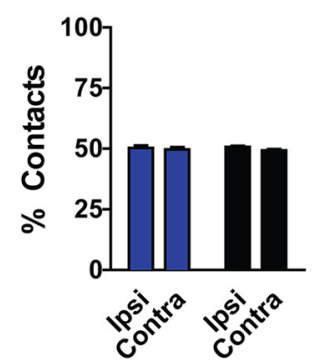

POST

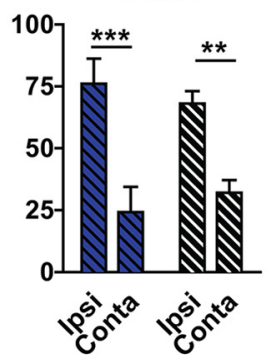

Figure 8. Analysis of motor function in DA-depleted VGLUT3 KO mice. A, Representative TH immunoreactivity across the striatum in WT (top) and KO (bottom) mice (left). Images were converted to binary data after subtraction of background. Total percentage of TH loss in the ipsilateral side of the dorsal striatum compared with contralateral controls from a subset of KO (red) and WT (black) mice used in ( $\boldsymbol{B} ; n=3 \mathrm{KO}$ and 4 WT mice; right). Data are presented as the mean \pm SEM and were analyzed by Student's $t$ test. $\boldsymbol{B}$, Spontaneous rotations in either the CW or CCW direction in the open field for VGLUT3 KO (red) and WT (black) mice ( $n=11$ mice per genotype; top). Rotations prelesion during the sleep cycle (left); rotations postlesion during the sleep cycle (center left); rotations prelesion during the awake cycle (center right); rotations postlesion during the awake cycle (right). Data were analyzed by 2-way ANOVA genotype $\times$ day with a Bonferroni post hoc test. Weight-bearing paw contacts while rearing in a cylinder for VGLUT3 KO (red) and WT (black) mice ( $n=10$ and 11 mice for KO and WT, respectively; bottom). Contacts prelesion during the sleep cycle (left); contacts postlesion during the sleep cycle (center left); contacts prelesion during the awake cycle (center right); contacts postlesion during the awake cycle (right). C, Spontaneous rotations in either the CW or CCW direction during a 15 min session in the open field for Vglut ${ }^{\text {fl/fli }}$; hat ${ }^{\mathrm{REESCre} /+}$ (blue) mice and Vglut ${ }^{\mathrm{fl} / \mathrm{fl}}$ (black) littermates (left). Weight-bearing paw contacts while rearing

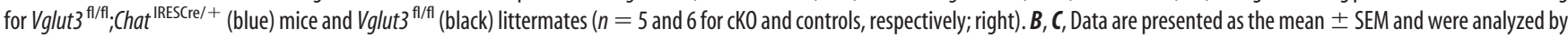
2-way ANOVA genotype $\times$ time with a Bonferroni post hoc test. n.s., Not significant; ${ }^{*} p<0.05$, ${ }^{* *} p<0.01,{ }^{* * *} p<0.001$. 

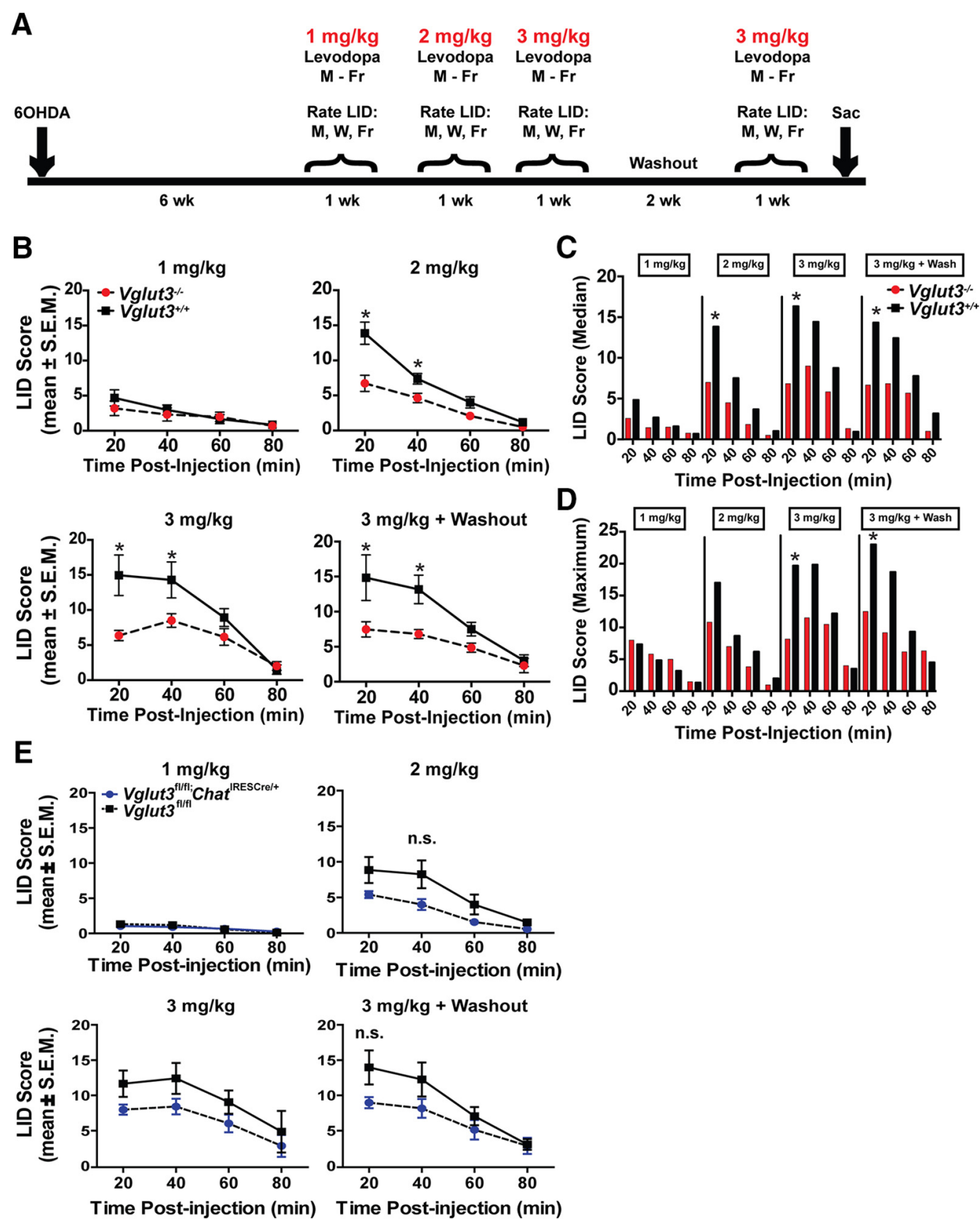

Figure 9. L-dopa-induced dyskinesias in VGLUT3 KO and WT littermates. $\boldsymbol{A}$, Time course of experimental design. $\boldsymbol{B}$, LID scores for VGLUT3 KO (red) and WT (black) littermates. Mean LID scores after injection of $1 \mathrm{mg} / \mathrm{kg} \mathrm{L-dopa} \mathrm{(top} \mathrm{left);} 2 \mathrm{mg} / \mathrm{kg} \mathrm{L-dopa} \mathrm{(top} \mathrm{right);} 3 \mathrm{mg} / \mathrm{kg} \mathrm{L-dopa} \mathrm{(bottom} \mathrm{left);} \mathrm{or} 2$ weeks after initial $3 \mathrm{mg} / \mathrm{kg}$ data collection $(n=4$ female and $2 \mathrm{males}$ and $n=1$ female and 3 males for KO and WTs, respectively; bottom right). Data were analyzed by 2-way ANOVA genotype $\times$ time with a Bonferroni post hoc test. C, Median LID scores for each dose of $\mathrm{L}-\mathrm{dopa}$ (1-3 mg/kg) across the 80 min testing period. D, Maximum LID scores observed for each dose of L-dopa (1 to $3 \mathrm{mg} / \mathrm{kg}$ ) across the 80 min testing period. E, LID scores for Vg/ut ${ }^{\mathrm{fl} / \mathrm{fl}} ;$ Chat ${ }^{\text {IRESCre/+ }}$ (blue) and Vglut $3^{\mathrm{fl} / \mathrm{fl}}$ (black) littermates ( $n=7$ and 5 for cK0 and control littermates, respectively). Mean LID scores from $3 \mathrm{~d}$ of testing every $20 \mathrm{~min}$ (80 min total) after injection of $1 \mathrm{mg} / \mathrm{kg} \mathrm{L-dopa} \mathrm{(top} \mathrm{left);}$ $2 \mathrm{mg} / \mathrm{kg} \mathrm{L-dopa} \mathrm{(top} \mathrm{right);} 3 \mathrm{mg} / \mathrm{kg} \mathrm{L-dopa} \mathrm{(bottom} \mathrm{left);} \mathrm{or} 2$ weeks after initial $3 \mathrm{mg} / \mathrm{kg}$ data collection (bottom right). $\boldsymbol{B}, \boldsymbol{E}$, Data are presented as the mean \pm SEM and were analyzed by 2 -way ANOVA genotype $\times$ time with a Bonferroni post hoc test. n.s., Not significant; ${ }^{*} p<0.05$.

2005). In this mutant, the defect appears to originate within the DA neurons themselves. Per1 KO mice demonstrate decreased DA levels and display an ADHD-like phenotype (Huang et al., 2015). Zebrafish mutants of Perlb show behaviors similar to the Per1 KO mice. Consistent with the behaviors, Per1b was shown to regulate the DA-related genes, monoamine oxidase and DA $\beta$ hydroxylase, as well as DA neuron development (Huang et al., 2015).

Only a few mouse mutants, like the VGLUT3 KO, exhibit a circadian-dependent locomotor phenotype without an overt re- lationship to altered circadian gene expression. For example, mice lacking the orphan G-protein-coupled receptor GPR88 show nocturnal hyperlocomotor activity due to deletion of the receptor in striatal output neurons, which produces an increase in the excitability of the neurons (Quintana et al., 2012). In this case, the increase in MSN activity appears to be sufficient to elicit the hyperactivity, but the basis for the circadian dependence is still not clear. One possibility is that controls on the locomotor circuit are simply less restrictive during the waking cycle, with fewer regulatory mechanisms in place to suppress activity, as op- 
Table 1. Summary of results for phenotypes tested (top) in global and conditional Vglut3 KO lines (left)

\begin{tabular}{|c|c|c|c|c|c|c|c|c|c|c|}
\hline Genotype & $\begin{array}{l}\text { Locomotor } \\
\text { activity }\end{array}$ & $\begin{array}{l}\mathrm{DA} \\
\text { release }\end{array}$ & $\begin{array}{l}\text { Tissue } \\
\text { content }\end{array}$ & $\begin{array}{l}\text { pTH } \\
\text { levels }\end{array}$ & $\begin{array}{l}\text { VAChT } \\
\text { levels }\end{array}$ & $\begin{array}{l}\text { Spine } \\
\text { density }\end{array}$ & $\begin{array}{l}\text { Rearing } \\
\text { habituation }\end{array}$ & $\begin{array}{l}\text { Pre-pulse } \\
\text { inhibition of } \\
\text { startle }\end{array}$ & $\begin{array}{l}\text { Parkinsonian } \\
\text { motor deficits }\end{array}$ & $\begin{array}{l}\text { L-Dopa } \\
\text { induced } \\
\text { dyskinesias }\end{array}$ \\
\hline Vglut3 ${ }^{-1-}$ & $\begin{array}{r}\text { Increased } \\
\text { (night) }\end{array}$ & $\begin{array}{r}\text { Increased } \\
\text { (night) }\end{array}$ & $\begin{array}{r}\text { Increased } \\
\text { (night) }\end{array}$ & $\begin{array}{r}\text { Increased } \\
\text { (night) }\end{array}$ & N.T. & $\begin{array}{r}\text { Increased } \\
\text { (night) }\end{array}$ & $\begin{array}{c}\text { Increased } \\
\text { (day) }\end{array}$ & N.T. & $\begin{array}{l}\text { Decreased } \\
\text { (day/night) }\end{array}$ & Decreased \\
\hline Vglut $3^{\mathrm{fl} / \mathrm{fl}} ;$ ChAT $^{\text {IRESCre/+ }}$ & N.E. & N.E. & N.E. & N.T. & N.E. & N.E. & $\begin{array}{l}\text { Increased } \\
\text { (day) }\end{array}$ & Decreased & N.E. & $\begin{array}{l}\text { Trending } \\
\text { decrease }\end{array}$ \\
\hline Vglut $^{\mathrm{f} / / \mathrm{fl}} ;$ Chat $^{\mathrm{Cre}(\mathrm{G}) /+}$ & N.E. & N.T. & N.T. & N.T. & Increased & N.T. & N.T. & N.E. & N.T. & N.T. \\
\hline
\end{tabular}

Results are indicated as "increased" or "decreased" and are defined as a difference in amplitude, value, or frequency compared to control littermates. "night" or "day" indicates the limb of the circadian cycle when the phenotype occurs, and some occur across the circadian cycle (night/day). If not specified, mice were tested during the day.

N.E. = no significant effect of genotype observed; N.T. = not tested.

posed to the sleep cycle, where the maintenance of a low activity state is desired. In the case of VGLUT3, our data suggest that the transporter normally acts to suppress DA levels and locomotor activity. This regulatory mechanism could itself be circadian in nature or it may be constant but constrained by additional mechanisms during the sleep cycle. Another factor that could influence the observed phenotypes is the sex of the animals. However, we observed no difference between male and female mice in the upregulation of the DA system, such as hyperlocomotion, or in the preservation of motor function after DA depletion. Future work to identify the cell population(s) responsible for the hyperdopaminergic phenotypes could provide insight into its apparent circadian dependence.

The normal locomotor activity and DA release in the dorsal striatum of mice lacking VGLUT3 specifically in cholinergic neurons was somewhat surprising given previous results showing that loss of VGLUT3 from CINs decreases cholinergic signaling (Gras et al., 2008; Nelson et al., 2014). Classic theories positioned $\mathrm{DA}$ and $\mathrm{ACh}$ as antagonists of one another and DA does inhibit CIN firing through activation of D2 receptors (DeBoer et al., 1996). However, recent studies suggest that ACh enhances DA release by activating nicotinic receptors on DA terminals (Exley et al., 2008; Exley et al., 2012; Threlfell et al., 2012). Therefore, decreasing ACh release, which occurs when VGLUT3 is deleted from CINs (Gras et al., 2008; Nelson et al., 2014), would be expected to attenuate DA release, perhaps resulting in hypolocomotor behavior. This prediction is based on in vitro recordings, whereas the in vivo circuitry is likely more complicated, thus raising the possibility of other behavior outcomes. Indeed, Guzman et al. (2011) reported no change in locomotor activity when VAChT was deleted specifically from CINs and suggested that the CIN-mediated glutamate release might be important instead. Our data now show definitively that the hyperlocomotor phenotype of the VGLUT3 KO mice has its origins in a noncholinergic neuron population(s) and that abolishing glutamate release and attenuating ACh release by CINs (and possibly basal forebrain cholinergic neurons) does not alter baseline locomotor activity.

The deletion of VGLUT3 specifically in cholinergic neurons does, however, alter two other behaviors: the prepulse inhibition of startle and habituation to a novel environment with repeated exposures. Disruption of PPI is often is a symptom of a schizophrenic state and decreased numbers of cholinergic interneurons have been observed in the striatum of schizophrenics (Holt et al., 1999). Mice with VAChT deleted in striatum or knocked down globally show no change in PPI (Guzman et al., 2011; Schmid et al., 2011). Interestingly, PPI was impaired in the Vglut $3^{\mathrm{fl} / \mathrm{fl}}$; Chat ${ }^{\mathrm{IRESCre} /+}$ mice, but not the Vglut $3^{\mathrm{fl} / \mathrm{fl}} ;$ Chat $^{\mathrm{Cre}(\mathrm{G}) /+}$ mice, which have elevated levels of VAChT and thus possibly increased ACh release, suggesting that either glutamate or ACh signaling by CINs is sufficient to maintain normal PPI.
Increased locomotor activity is usually reflected by an increase in rearing behavior. However, VGLUT3 KO mice do not demonstrate a robust increase in rearing behavior at night, when locomotor activity is greatly enhanced. Moreover, during the daytime, both $\mathrm{KO}$ and Vglut $^{\mathrm{fl} / \mathrm{fl}}$; Chat ${ }^{\mathrm{IRESCre} /+}$ mice demonstrate a decrease in rearing activity, which increases over repeated daily exposures to the novel environment. Therefore it seems that loss of VGLUT3 from cholinergic neurons mediates the suppression of rearing; however, other modulatory systems, such as serotonergic neurons, may also play a role (Amilhon et al., 2010).

Changes in MSN spine density are a common feature of manipulations that alter DA levels, for example, with repeated cocaine use or in Parkinson's disease. Here, we show that the MSN spine density changes in concert with the circadian cycle. Spines are increased in the dorsal and ventral striatum during the night, when DA levels are elevated, and then return to baseline levels during the day. Electrophysiological recordings show that the enhanced spines are likely immature, consistent with their dynamic nature. Repeated cocaine administration increases the formation of unstable dendritic spines in ventral MSNs, which contain only NMDA and not AMPA receptors and are thus referred to as silent synapses (Huang et al., 2009; Brown et al., 2011; Lee and Dong, 2011; Zhang et al., 2012; Lee et al., 2013). A subsequent long-term absence of cocaine triggers silent synapses to mature. It thus seems possible that the circadian-dependent increase in DA in the VGLUT3 KO promotes the formation of transient, immature synapses that never experience the right conditions to mature.

One of our most striking findings is the absence of motor deficits in VGLUT3 KO mice in a model of Parkinson's disease. The Vglut $^{\mathrm{f} / \mathrm{fl} \mathrm{l}} ;$ Chat ${ }^{\mathrm{IRESCre} /+}$ mice did not show this effect, indicating that the loss of VGLUT3 from cholinergic neurons is not sufficient to ameliorate the motor symptoms. A likely candidate is instead the increased DA release that occurs in the dorsal striatum of the global $\mathrm{KO}$ during the waking cycle, although, curiously, motor behaviors were also normal during the day. DA depletion is known to produce a decrease in MSN spine density that is compensated for by an increase in the strength of cortical and thalamic glutamatergic inputs (Villalba and Smith, 2013). It is thus intriguing to speculate that the increased density of immature spines in the global KO is translated into an increase in mature spines upon DA depletion, thus providing a mechanism for the improved motor symptoms throughout the circadian cycle.

The VGLUT3 KO mice also showed a marked attenuation of L-dopa dyskinesias. A number of mechanisms have been reported to attenuate this unwanted motor behavior, including the ablation and inhibition of striatal cholinergic interneurons (Won et al., 2014; Lim et al., 2015), as well as disruption of D1 MSN signaling with a conditional KO of DARPP-32 (Bateup et al., 2010). Our findings show a trend toward a contribution by 
VGLUT3 expressed by CINs, but additional work is required to fully understand the contribution of CIN-mediated signaling and other VGLUT3-mediated signaling mechanisms to the development and expression of LID.

In conclusion, our work here shows that VGLUT3 profoundly regulates the activity of the midbrain DA system in a circadiandependent manner. This modulation will have a broad impact on behavior because the circadian-dependent regulation of the basal ganglia affects many aspects of brain function, including addiction, psychiatric conditions, and movement disorders (Edgar and McClung 2013). In addition, the development of mice with a cholinergic-specific deletion of VGLUT3 now allows us to rule out the prevailing hypothesis that VGLUT3 in CINs affects DA release in the dorsal striatum and baseline locomotor activity. Finally, we demonstrate that the transporter strongly influences mechanisms of neural plasticity that underlie motor deficits and L-dopa-mediated dyskinesias in a Parkinson's disease model. These novel findings open new avenues for further experimental investigation and the development of better treatment options.

\section{References}

Amilhon B, Lepicard E, Renoir T, Mongeau R, Popa D, Poirel O, Miot S, Gras C, Gardier AM, Gallego J, Hamon M, Lanfumey L, Gasnier B, Giros B, El Mestikawy S (2010) VGLUT3 (vesicular glutamate transporter type 3) contributes to the regulation of serotonergic transmission and anxiety. J Neurosci 30:2198-2210. CrossRef Medline

Bastide MF, Meissner WG, Picconi B, Fasano S, Fernagut PO, Feyder M, Francardo V, Alcacer C, Ding Y, Brambilla R, Fisone G, Jon Stoessl A, Bourdenx M, Engeln M, Navailles S, De Deurwaerdère P, Ko WK, Simola N, Morelli M, Groc L, et al. (2015) Pathophysiology of L-dopa-induced motor and non-motor complications in Parkinson's disease. Prog Neurobiol 132:96-168. CrossRef Medline

Bateup HS, Santini E, Shen W, Birnbaum S, Valjent E, Surmeier DJ, Fisone G, Nestler EJ, Greengard P (2010) Distinct subclasses of medium spiny neurons differentially regulate striatal motor behaviors. Proc Natl Acad Sci U S A 107:14845-14850. CrossRef Medline

Bello EP, Mateo Y, Gelman DM, Noaín D, Shin JH, Low MJ, Alvarez VA, Lovinger DM, Rubinstein M (2011) Cocaine supersensitivity and enhanced motivation for reward in mice lacking dopamine D2 autoreceptors. Nat Neurosci 14:1033-1038. CrossRef Medline

Brown TE, Lee BR, Mu P, Ferguson D, Dietz D, Ohnishi YN, Lin Y, Suska A, Ishikawa M, Huang YH, Shen H, Kalivas PW, Sorg BA, Zukin RS, Nestler EJ, Dong Y, Schlüter OM (2011) A silent synapse-based mechanism for cocaine-induced locomotor sensitization. J Neurosci 31:8163-8174. CrossRef Medline

Cachope R, Mateo Y, Mathur BN, Irving J, Wang HL, Morales M, Lovinger DM, Cheer JF (2012) Selective activation of cholinergic interneurons enhances accumbal phasic dopamine release: setting the tone for reward processing. Cell Rep 2:33-41. CrossRef Medline

Cazorla M, Shegda M, Ramesh B, Harrison NL, Kellendonk C (2012) Striatal D2 receptors regulate dendritic morphology of medium spiny neurons via Kir2 channels. J Neurosci 32:2398-2409. CrossRef Medline

Cenci MA, Whishaw IQ, Schallert T (2002) Animal models of neurological deficits: how relevant is the rat? Nat Rev Neurosci 3:574-579. CrossRef Medline

Centonze D, Picconi B, Gubellini P, Bernardi G, Calabresi P (2001) Dopaminergic control of synaptic plasticity in the dorsal striatum. Eur J Neurosci 13:1071-1077. CrossRef Medline

Crittenden JR, Lacey CJ, Lee T, Bowden HA, Graybiel AM (2014) Severe drug-induced repetitive behaviors and striatal overexpression of VAChT in ChAT-ChR2-EYFP BAC transgenic mice. Front Neural Circuits 8:57. Medline

DeBoer P, Heeringa MJ, Abercrombie ED (1996) Spontaneous release of acetylcholine in striatum is preferentially regulated by inhibitory dopamine D2 receptors. Eur J Pharmacol 317:257-262. CrossRef Medline

Ding J, Guzman JN, Tkatch T, Chen S, Goldberg JA, Ebert PJ, Levitt P, Wilson CJ, Hamm HE, Surmeier DJ (2006) RGS4-dependent attenuation of M4 autoreceptor function in striatal cholinergic interneurons following dopamine depletion. Nat Neurosci 9:832-842. CrossRef Medline
Edgar N, McClung CA (2013) Major depressive disorder: a loss of circadian synchrony? Bioessays 35:940-944. CrossRef Medline

Evetts KD, Uretsky NJ, Iversen LL, Iversen SD (1970) Effects of 6-hydroxydopamine on CNS catecholamines, spontaneous motor activity and amphetamine induced hyperactivity in rats. Nature 225:961-962. CrossRef Medline

Exley R, Clements MA, Hartung H, McIntosh JM, Cragg SJ (2008) Alpha6containing nicotinic acetylcholine receptors dominate the nicotine control of dopamine neurotransmission in nucleus accumbens. Neuropsychopharmacology 33:2158-2166. CrossRef Medline

Exley R, McIntosh JM, Marks MJ, Maskos U, Cragg SJ (2012) Striatal alpha5 nicotinic receptor subunit regulates dopamine transmission in dorsal striatum. J Neurosci 32:2352-2356. CrossRef Medline

Fasano C, Bourque MJ, Lapointe G, Leo D, Thibault D, Haber M, Kortleven C, Desgroseillers L, Murai KK, Trudeau LÉ (2013) Dopamine facilitates dendritic spine formation by cultured striatal medium spiny neurons through both D1 and D2 dopamine receptors. Neuropharmacology 67: 432-443. CrossRef Medline

Ferris MJ, España RA, Locke JL, Konstantopoulos JK, Rose JH, Chen R, Jones SR (2014) Dopamine transporters govern diurnal variation in extracellular dopamine tone. Proc Natl Acad Sci U S A 111:E2751-E2759. CrossRef Medline

Fremeau RT Jr, Burman J, Qureshi T, Tran CH, Proctor J, Johnson J, Zhang H, Sulzer D, Copenhagen DR, Storm-Mathisen J, Reimer RJ, Chaudhry FA, Edwards RH (2002) The identification of vesicular glutamate transporter 3 suggests novel modes of signaling by glutamate. Proc Natl Acad Sci U S A 99:14488-14493. CrossRef Medline

Fremeau RT Jr, Voglmaier S, Seal RP, Edwards RH (2004) VGLUTs define subsets of excitatory neurons and suggest novel roles for glutamate. Trends Neurosci 27:98-103. CrossRef Medline

Glajch KE, Fleming SM, Surmeier DJ, Osten P (2012) Sensorimotor assessment of the unilateral 6-hydroxydopamine mouse model of Parkinson's disease. Behav Brain Res 230:309-316. CrossRef Medline

Gomeza J, Zhang L, Kostenis E, Felder C, Bymaster F, Brodkin J, Shannon H, Xia B, Deng C, Wess J (1999) Enhancement of D1 dopamine receptormediated locomotor stimulation in $\mathrm{M}(4)$ muscarinic acetylcholine receptor knock-out mice. Proc Natl Acad Sci U S A 96:10483-10488. CrossRef Medline

Gras C, Herzog E, Bellenchi GC, Bernard V, Ravassard P, Pohl M, Gasnier B, Giros B, El Mestikawy S (2002) A third vesicular glutamate transporter expressed by cholinergic and serotoninergic neurons. J Neurosci 22:5442-5451. Medline

Gras C, Amilhon B, Lepicard EM, Poirel O, Vinatier J, Herbin M, Dumas S, Tzavara ET, Wade MR, Nomikos GG, Hanoun N, Saurini F, Kemel ML, Gasnier B, Giros B, El Mestikawy S (2008) The vesicular glutamate transporter VGLUT3 synergizes striatal acetylcholine tone. Nat Neurosci 11:292-300. CrossRef Medline

Grealish S, Xie L, Kelly M, Dowd E (2008) Unilateral axonal or terminal injection of 6-hydroxydopamine causes rapid-onset nigrostriatal degeneration and contralateral motor impairments in the rat. Brain Res Bull 77:312-319. CrossRef Medline

Grimes WN, Seal RP, Oesch N, Edwards RH, Diamond JS (2011) Genetic targeting and physiological features of VGLUT3+ amacrine cells. Vis Neurosci 28:381-392. CrossRef Medline

Gritti I, Henny P, Galloni F, Mainville L, Mariotti M, Jones BE (2006) Stereological estimates of the basal forebrain cell population in the rat, including neurons containing choline acetyltransferase, glutamic acid decarboxylase or phosphate-activated glutaminase and colocalizing vesicular glutamate transporters. Neuroscience 143:1051-1064. CrossRef Medline

Gubernator NG, Zhang H, Staal RG, Mosharov EV, Pereira DB, Yue M, Balsanek V, Vadola PA, Mukherjee B, Edwards RH, Sulzer D, Sames D (2009) Fluorescent false neurotransmitters visualize dopamine release from individual presynaptic terminals. Science 324:1441-1444. CrossRef Medline

Guzman MS, De Jaeger X, Raulic S, Souza IA, Li AX, Schmid S, Menon RS, Gainetdinov RR, Caron MG, Bartha R, Prado VF, Prado MA (2011) Elimination of the vesicular acetylcholine transporter in the striatum reveals regulation of behaviour by cholinergic-glutamatergic co-transmission. PLoS Biol 9:e1001194. CrossRef Medline

Higley MJ, Gittis AH, Oldenburg IA, Balthasar N, Seal RP, Edwards RH, Lowell BB, Kreitzer AC, Sabatini BL (2011) Cholinergic interneurons mediate fast VGluT3-dependent glutamatergic transmission in the striatum. PLoS One 6:e19155. CrossRef Medline 
Holt DJ, Herman MM, Hyde TM, Kleinman JE, Sinton CM, German DC, Hersh LB, Graybiel AM, Saper CB (1999) Evidence for a deficit in cholinergic interneurons in the striatum in schizophrenia. Neuroscience 94: 21-31. CrossRef Medline

Huang J, Zhong Z, Wang M, Chen X, Tan Y, Zhang S, He W, He X, Huang G, $\mathrm{Lu} \mathrm{H}$, Wu P, Che Y, Yan YL, Postlethwait JH, Chen W, Wang H (2015) Circadian modulation of dopamine levels and dopaminergic neuron development contributes to attention deficiency and hyperactive behavior. J Neurosci 35:2572-2587. CrossRef Medline

Huang YH, Lin Y, Mu P, Lee BR, Brown TE, Wayman G, Marie H, Liu W, YanZ, Sorg BA, Schlüter OM, Zukin RS, Dong Y (2009) In vivo cocaine experience generates silent synapses. Neuron 63:40-47. CrossRef Medline

Ishikawa M, Otaka M, Huang YH, Neumann PA, Winters BD, Grace AA, Schlüter OM, Dong Y (2013) Dopamine triggers heterosynaptic plasticity. J Neurosci 33:6759-6765. CrossRef Medline

Kolisnyk B, Guzman MS, Raulic S, Fan J, Magalhães AC, Feng G, Gros R, Prado VF, Prado MA (2013) ChAT-ChR2-EYFP mice have enhanced motor endurance but show deficits in attention and several additional cognitive domains. J Neurosci 33:10427-10438. CrossRef Medline

Laplante F, Lappi DA, Sullivan RM (2011) Cholinergic depletion in the nucleus accumbens: effects on amphetamine response and sensorimotor gating. Prog Neuropsychopharmacol Biol Psychiatry 35:501-509. CrossRef Medline

Lee BR, Dong Y (2011) Cocaine-induced metaplasticity in the nucleus accumbens: silent synapse and beyond. Neuropharmacology 61: 1060-1069. CrossRef Medline

Lee BR, Ma YY, Huang YH, Wang X, Otaka M, Ishikawa M, Neumann PA, Graziane NM, Brown TE, Suska A, Guo C, Lobo MK, Sesack SR, Wolf ME, Nestler EJ, Shaham Y, Schlüter OM, Dong Y (2013) Maturation of silent synapses in amygdala-accumbens projection contributes to incubation of cocaine craving. Nat Neurosci 16:1644-1651. CrossRef Medline

Lim SA, Xia R, Ding Y, Won L, Ray WJ, Hitchcock SA, McGehee DS, Kang UJ (2015) Enhanced histamine H2 excitation of striatal cholinergic interneurons in 1-DOPA-induced dyskinesia. Neurobiol Dis 76:67-76. CrossRef Medline

Madhavan L, Daley BF, Sortwell CE, Collier TJ (2012) Endogenous neural precursors influence grafted neural stem cells and contribute to neuroprotection in the parkinsonian rat. Eur J Neurosci 35:883-895. CrossRef Medline

Madisen L, Zwingman TA, Sunkin SM, Oh SW, Zariwala HA, Gu H, Ng LL, Palmiter RD, Hawrylycz MJ, Jones AR, Lein ES, Zeng H (2010) A robust and high-throughput Cre reporting and characterization system for the whole mouse brain. Nat Neurosci 13:133-140. Medline

Maries E, Kordower JH, Chu Y, Collier TJ, Sortwell CE, Olaru E, Shannon K, Steece-Collier K (2006) Focal not widespread grafts induce novel dyskinetic behavior in parkinsonian rats. Neurobiol Dis 21:165-180. CrossRef Medline

McClung CA (2013) How might circadian rhythms control mood? Let me count the ways. Biol Psychiatry 74:242-249. CrossRef Medline

McClung CA, Sidiropoulou K, Vitaterna M, Takahashi JS, White FJ, Cooper DC, Nestler EJ (2005) Regulation of dopaminergic transmission and cocaine reward by the Clock gene. Proc Natl Acad Sci U S A 102:9377-9381. CrossRef Medline

Nagy PM, Aubert I (2012) Overexpression of the vesicular acetylcholine transporter increased acetylcholine release in the hippocampus. Neuroscience 218:1-11. CrossRef Medline

Nelson AB, Bussert TG, Kreitzer AC, Seal RP (2014) Striatal cholinergic neurotransmission requires VGLUT3. J Neurosci 34:8772-8777. CrossRef Medline

Ng KY, Chase TN, Colburn RW, Kopin IJ (1971) Dopamine: stimulation-induced release from central neurons. Science 172:487-489. CrossRef Medline

Nickerson PA, Guerci A, El Mestikawy S, Semba K (2006) Vesicular glutamate transporter 3 immunoreactivity is present in cholinergic basal forebrain neurons projecting to the basolateral amygdala in rat. J Comp Neurol 498:690-711. CrossRef Medline

Peirs C, Williams SP, Zhao X, Walsh CE, Gedeon JY, Cagle NE, Goldring AC, Hioki H, Liu Z, Marell PS, Seal RP (2015) Dorsal horn circuits for persistent mechanical pain. Neuron 87:797-812. CrossRef Medline

Quintana A, Sanz E, Wang W, Storey GP, Güler AD, Wanat MJ, Roller BA, La Torre
A, Amieux PS, McKnight GS, Bamford NS, Palmiter RD (2012) Lack of GPR88 enhances medium spiny neuron activity and alters motor- and cue-dependent behaviors. Nat Neurosci 15:1547-1555. CrossRef Medline

Rodriguez PC, Pereira DB, Borgkvist A, Wong MY, Barnard C, Sonders MS, Zhang H, Sames D, Sulzer D (2013) Fluorescent dopamine tracer resolves individual dopaminergic synapses and their activity in the brain. Proc Natl Acad Sci U S A 110:870-875. CrossRef Medline

Rossi J, Balthasar N, Olson D, Scott M, Berglund E, Lee CE, Choi MJ, Lauzon D, Lowell BB, Elmquist JK (2011) Melanocortin-4 receptors expressed by cholinergic neurons regulate energy balance and glucose homeostasis. Cell Metab 13:195-204. CrossRef Medline

Schäfer MK, Varoqui H, Defamie N, Weihe E, Erickson JD (2002) Molecular cloning and functional identification of mouse vesicular glutamate transporter 3 and its expression in subsets of novel excitatory neurons. J Biol Chem 277:50734-50748. CrossRef Medline

Schmid S, Azzopardi E, De Jaeger X, Prado MA, Prado VF (2011) VAChT knock-down mice show normal prepulse inhibition but disrupted longterm habituation. Genes Brain Behav 10:457-464. CrossRef Medline

Seal RP, Akil O, Yi E, Weber CM, Grant L, Yoo J, Clause A, Kandler K, Noebels JL, Glowatzki E, Lustig LR, Edwards RH (2008) Sensorineural deafness and seizures in mice lacking vesicular glutamate transporter 3. Neuron 57:263-275. CrossRef Medline

Soderstrom KE, O'Malley JA, Levine ND, Sortwell CE, Collier TJ, SteeceCollier K (2010) Impact of dendritic spine preservation in medium spiny neurons on dopamine graft efficacy and the expression of dyskinesias in parkinsonian rats. Eur J Neurosci 31:478-490. CrossRef Medline

Steece-Collier K, Maries E, Kordower JH (2002) Etiology of Parkinson's disease: genetics and environment revisited. Proc Natl Acad Sci U S A 99:13972-13974. CrossRef Medline

Steece-Collier K, Collier TJ, Danielson PD, Kurlan R, Yurek DM, Sladek JR Jr (2003) Embryonic mesencephalic grafts increase levodopa-induced forelimb hyperkinesia in parkinsonian rats. Mov Disord 18:1442-1454. CrossRef Medline

Surmeier DJ, Graybiel AM (2012) A feud that wasn't: acetylcholine evokes dopamine release in the striatum. Neuron 75:1-3. CrossRef Medline

Threlfell S, Lalic T, Platt NJ, Jennings KA, Deisseroth K, Cragg SJ (2012) Striatal dopamine release is triggered by synchronized activity in cholinergic interneurons. Neuron 75:58-64. CrossRef Medline

Villalba RM, Smith Y (2013) Differential striatal spine pathology in Parkinson's disease and cocaine addiction: a key role of dopamine? Neuroscience 251:2-20. CrossRef Medline

Von Voigtlander PF, Moore KE (1973) Turning behavior of mice with unilateral 6-hydroxydopamine lesions in the striatum: effects of apomorphine, L-DOPA, amanthadine, amphetamine and other psychomotor stimulants. Neuropharmacology 12:451-462. CrossRef Medline

Wang HL, Morales M (2009) Pedunculopontine and laterodorsal tegmental nuclei contain distinct populations of cholinergic, glutamatergic and GABAergic neurons in the rat. Eur J Neurosci 29:340-358. CrossRef Medline

Won L, Ding Y, Singh P, Kang UJ (2014) Striatal cholinergic cell ablation attenuates L-DOPA induced dyskinesia in Parkinsonian mice. J Neurosci 34:3090-3094. CrossRef Medline

Zhang H, Sulzer D (2003) Glutamate spillover in the striatum depresses dopaminergic transmission by activating group I metabotropic glutamate receptors. J Neurosci 23:10585-10592. Medline

Zhang H, Sulzer D (2004) Frequency-dependent modulation of dopamine release by nicotine. Nat Neurosci 7:581-582. CrossRef Medline

Zhang L, Dong Y, Doyon WM, Dani JA (2012) Withdrawal from chronic nicotine exposure alters dopamine signaling dynamics in the nucleus accumbens. Biol Psychiatry 71:184-191. CrossRef Medline

Zhou FM, Wilson CJ, Dani JA (2002) Cholinergic interneuron characteristics and nicotinic properties in the striatum. J Neurobiol 53:590-605. CrossRef Medline

Zhuang X, Mazzoni P, Kang UJ (2013) The role of neuroplasticity in dopaminergic therapy for Parkinson disease. Nat Rev Neurol 9:248-256. CrossRef Medline 